\title{
Economic policy uncertainty and investment in Spain
}

\author{
Daniel Dejuan-Bitria ${ }^{1}$. Corinna Ghirelli ${ }^{2}$
}

Received: 16 November 2020 / Accepted: 8 May 2021 / Published online: 15 June 2021

(c) The Author(s) 2021

\begin{abstract}
The aim of this paper is to investigate the effect of economic policy uncertainty on firms' investment decisions. We focus on Spain for the period 1998-2014. To measure policy-related uncertainty, we borrow the economic policy uncertainty (EPU) indicator available for this country. We find strong evidence that uncertainty reduces corporate investment. This relationship appears to be nonlinear, being the marginal effect of uncertainty attenuated toward zero during periods of high uncertainty levels. Furthermore, the heterogeneous results suggest that the adverse effect of uncertainty is particularly relevant for highly vulnerable firms. Overall, these results are consistent with the hypotheses that economic policy-related uncertainty reduces corporate investment through increases in precautionary savings or to worsening of credit conditions.
\end{abstract}

Keywords Corporate investment · Economic policy uncertainty $\cdot$ EPU $\cdot$ Financial frictions

JEL Classification D80 $\cdot$ E22 $\cdot$ G18 $\cdot$ G31 $\cdot$ G38

Daniel Dejuan-Bitria: Part of this research was carried out while working at the Bank of Spain, Directorate General Economics, Statistics and Research.

We are grateful to Roberto Blanco, Fabrizio Coricelli, Carmen Martínez Carrascal, Enrique Moral, Alberto Urtasun, and Martin Wagner for helpful discussions. We also thank seminar participants at the internal seminars of the Bank of Spain and at the second workshop of the European Network for Research on Investment (ENRI) organized by the European Investment Bank (Luxemburg, 2018) for their useful comments and suggestions. Any views expressed in this paper are those of the authors and do not reflect those of the Bank of Spain or the European System of Central Banks (ESCB).

$\bowtie$ Corinna Ghirelli

corinna.ghirelli@bde.es

Daniel Dejuan-Bitria

daniel.dejuan@barcelonagse.eu

1 University Pompeu Fabra, Ramon Trias Fargas, 25-27, 08005 Barcelona, Spain

2 Bank of Spain, Directorate General Economics, Statistics and Research, Calle de Alcalá 48, Madrid, Spain 


\section{Introduction}

Corporate investment is a key factor in sustaining the productivity and long-term economic growth of firms. The slow recovery of corporate investment in the aftermath of the Great Recession has renewed interest in the drivers of corporate investment and spurred the debate on the effects of uncertainty on real economic variables. ${ }^{1}$ The working hypothesis is that uncertainty exacerbates the consequences of downturns (Bloom 2014). In particular, aggregate uncertainty has been increasingly recognized as an additional relevant determinant of investment decisions.

New evidence from the European Investment Bank Group Survey on Investment and Investment Finance (EIBIS) supports the hypothesis that uncertainty affects investment in Europe. ${ }^{2}$ According to the 2016 wave, uncertainty is the most reported obstacle for long-term investment in the European area. $75 \%$ of European firms report that uncertainty about the future has been an obstacle in their investment activities, followed by availability of staff with the right skills (71\%), and business regulation (64\%). In addition, the political and regulatory climate is seen as a major impediment to carrying out planned investment in the short term.

A growing empirical literature focuses on the impact of aggregate uncertainty on macroeconomic dynamics. ${ }^{3}$ In particular, much attention has been devoted to the relationship between uncertainty and investment, being mostly studied through the lens of the real option literature (wait-and-see effect) and from a macro-perspective. In this paper, we further explore this relationship and contribute to the literature in two main ways. First, we assess the role of risk aversion and financial frictions as potential channels through which uncertainty shocks may be amplified. Second, only a few studies investigate this issue from a micro-perspective, focusing on the USA (Baker et al. 2016; Gulen and Ion 2016; Bonaime et al. 2018). To the best of our knowledge, there is no evidence available on the impact of economic policy uncertainty on investment at the micro-level for Europe. ${ }^{4}$ We aim to fill this gap by providing new evidence for Spain. Notably, our population coverage complements the existing evidence that refers to publicly listed US firms. On the one hand, SMEs represent more than $95 \%$ of all firms in our sample. On the other, the financial friction channel may be extremely relevant in Spain since credit borrowing is by far the most important source of external finance for corporate investment. ${ }^{5}$

\footnotetext{
1 The recovery was sluggish especially in USA and Europe. In Spain, it started in 2013 after the sovereign debt crisis and investment reached the pre-crisis level in 2017. In many other EU countries, the recovery was slower.

2 EIBIS is a EU-wide firm-level survey that collects information on firms' investment activities, their financing requirements, and the difficulties they face.

3 For example, Bloom et al. (2007); Bloom (2009), Bachmann et al. (2013), Jurado et al. (2015), Basu and Bundick (2017). For Spain, see Gil et al. (2017), Ghirelli et al. (2019).

4 A number of papers study the impact of firm-level uncertainty on investment: e.g., Guiso and Parigi (1999), Bontempi et al. (2010) for Italy.

5 According to the EIBIS survey, $40 \%$ of investment by Spanish firms in 2015 relied on external finance. Spain is ranked fourth among EU countries in terms of external finance usage. $75 \%$ of external finance relates to bank loans. This makes Spain one of the EU countries relying most intensively on bank lending.
} 
Uncertainty is not a clear-cut concept. ${ }^{6}$ We focus on economic policy uncertainty, which refers to situations characterized by increased dispersion in agents' expectations about governments' future economic policy stands. The intuition is that greater uncertainty about possible changes in government economic policies may induce firms to delay investment so as to gain additional information or may prevent them from investing due to increased financial frictions or increased risk aversion.

Measuring uncertainty is a major difficulty of this stream of the literature. ${ }^{7}$ To measure it, we we borrow the Economic Policy Uncertainty (EPU) index by Ghirelli et al. (2019). This index has been constructed for Spain following Baker et al. (2016), which provide the most influential methodology to measure economic policy uncertainty. ${ }^{8}$

In an nutshell, the Baker et al.'s (2016) EPU index is based on the volume of newspapers' articles containing words related to "economy," "policy," and "uncertainty." In their empirical application, Baker et al. (2016) use this indicator to document the real effects of policy uncertainty based on firm-level data. In the same spirit, Gulen and Ion (2016) investigate the impact of uncertainty on US corporate investment using the Baker et al.'s (2016) EPU index. ${ }^{9}$ Both studies document the adverse effect of the EPU index on the corporate investment of publicly listed firms in the USA. In line with the wait-and-see channel, this effect is particularly strong for firms with a high degree of irreversibility and those dependent on government spending.

We estimate a classical investment model augmented to explicitly account for the impact of aggregate factors in order to identify the average effect of economic policy uncertainty on the gross investment-to-capital ratio. Our sample is based on annual firm-level data from the Central Balance Sheet Data Office Survey of the Bank of Spain, for the period 1998 to 2014 . We use panel data methods to account for firm-specific unobserved heterogeneity. According to our baseline model, an increase in uncertainty of one unit decreases the investment rate by about 4.7 percentage points. To give a sense of the magnitude of this effect, consider that the EPU index increased by one unit between 2008 and 2011, i.e., at the start of the financial crisis. Furthermore, our analysis suggests that the relationship between uncertainty and corporate investment appears to be nonlinear. The marginal effect of uncertainty gets attenuated toward zero during periods of high uncertainty levels. Finally, we study heterogeneous effects along a number of cross-sectional dimensions such as its financial position, whether the firm belongs to a corporate group and the firm's orientation to export. We find that exporting firms are less affected than non-exporting firms, which can be explained by the fact that exporters may be less sensitive to domestic policy uncertainty since they operate

\footnotetext{
6 The literature proposes alternative proxies to capture specific facets of uncertainty: e.g., stock market volatility (Bloom 2009); expectations dispersion (Bachmann et al. 2013); newspaper-based index of policy uncertainty (Baker et al. 2016); and volatility of unforecastable components of several time series (Jurado et al. 2015).

7 Julio and Yook (2012) study the impact of policy uncertainty on corporate investment using elections as a source of exogenous variation in policy uncertainty. In a similar vein, other studies use elections as an instrument for political uncertainty (Julio and Yook 2016; Jens 2017). Shoag and Veuger (2016) construct a measure of US state-level uncertainty based on counts of local newspaper articles related to economic uncertainty and investigate its effect on state-level unemployment.

8 Baker et al. (2016) construct the EPU index for the USA and many other countries. These indexes are available online at http://www.policyuncertainty.com/index.html.

9 Bonaime et al. (2018) use the same index to study uncertainty effects on mergers and acquisitions.
} 
in foreign markets. In addition, small- and medium-sized enterprises (SMEs) and firms in poorer financial condition decrease investment significantly more than their counterparts, while firms that belong to corporate groups are less affected by policy uncertainty shocks than non-member firms. Belonging to corporate groups, a practice that has been increasing in Spain since the Great Recession may be a strategy for small firms to overcome informational and financial frictions in the credit market. To the extent that belonging to corporate groups facilitates access to banking finance, both results are consistent with the idea that part of the explanation for the negative relation between uncertainty and corporate investment may be related to the financial frictions channel (supply-driven credit tightening). This is also in line with the risk-aversion story: In this case, the decrease in investment may occur via demand-driven loan reductions for financing investment projects or an increase in precautionary savings.

The rest of the article is organized as follows. Sect. 2 briefly reviews the literature related to the different channels through which uncertainty may affect investment. In Sect. 3, we present our uncertainty indicator and the firm-level data used in the analysis. The empirical strategy is presented in Sect. 4. In Sect. 5, we discuss the results. Robustness tests are presented in Sect. 6, and Sect. 7 offers some concluding remarks.

\section{Propagation channels of uncertainty}

The literature focuses on the relationship between uncertainty and investment proposes different channels that may be in place. On the one hand, the wait-and-see effect is framed within the real option literature. This channel has been widely documented, both theoretically and empirically. Another stream in the literature stresses the role of financial frictions and risk aversion as alternative transmission mechanisms of policy uncertainty in firm-level investment. Our paper is novel in assessing the relevance of these two channels through which uncertainty shocks may be amplified.

According to the real option literature, in the presence of even partially irreversible projects and informational frictions, uncertainty may increase the incentives of a firm to delay investment projects. Under high levels of uncertainty, firms exercise "the option value of waiting," which ensures access to additional information. This generates the so-called wait-and-see effect, which impacts both the timing and level of investment (e.g., Bernanke 1983; Bertola and Caballero 1994; Abel and Eberly 1994; Dixit and Pindyck 1991).

Recent empirical work seems to corroborate the relevance of this channel. Gulen and Ion (2016) and Baker et al. (2016) study the relationship between firm-level capital investment and policy-related uncertainty for publicly listed firms in the USA. They use the aforementioned Baker et al.'s (2016) EPU index to measure uncertainty. Gulen and Ion (2016) find a strong negative relationship between aggregated policy uncertainty and corporate investment. In addition, these authors study potential crosssectional heterogeneity in the uncertainty-investment relationship. The negative effect is greater for firms facing a high degree of investment irreversibility and for those that are more dependent on government spending. Their results provide evidence that the wait-and-see effect may be an important channel for US-listed firms. 
Baker et al. (2016) slightly change the research question, shifting the focus from studying the average effect of policy uncertainty on corporate investment to studying the particular channels through which the adverse effect of policy uncertainty materializes. They also focus on the differential effect of policy uncertainty along a measure of exposure to government purchases. The working hypothesis is that policy uncertainty matters most for policy-sensitive sectors and firms react to high levels of policy uncertainty by postponing investment decisions. They find that the negative effect of policy uncertainty on investment rate and employment growth is most pronounced among firms largely exposed to government purchases, which is also in favor of real option models.

All in all, the existing evidence for publicly listed firms in the USA corroborates the wait-and-see effect. However, it does not discuss the other two channels proposed by the literature, namely financial frictions and risk aversion.

A recent branch of the literature points toward financial distortions as the most important mechanism through which uncertainty may affect investment decisions (Gilchrist et al. 2014; Christiano et al. 2014; Arellano et al. 2019). Financial frictions may exacerbate the negative effect of uncertainty. Arguably, periods of higher uncertainty, conditional on other determinants, may affect access to credit as banks become more restrictive in granting loans. Thus, the "financial frictions" channel highlights the role of the effective supply of credit as a main channel through which uncertainty affects investment. In this case, the decision to delay investment stems from the credit supply side and is sub-optimal from a firm's point of view. The role of uncertainty in credit supply tightening has been empirically corroborated (e.g., Alessandri and Bottero 2020; Buch et al. 2015).

Finally, another stream in the literature suggests that firms react to high uncertainty with precautionary savings. This holds if firms are risk-averse (Jurado et al. 2015; Femminis 2012; Saltari and Ticchi 2007). ${ }^{10}$ Risk aversion may be sharpened in periods of high uncertainty, and this may lead firms to curtail their investment. Notably, this channel suggests that credit shrinkage associated with high uncertainty periods may be demand driven, as opposed to the financial frictions story, which offers a supply-driven explanation of credit crunches.

In this paper, we posit that the financial frictions and risk-aversion channels may be relevant to explain the adverse effect of policy uncertainty on investment. As long as firms rely on external funds to finance their investment projects and uncertainty shocks imply credit tightening, firms that are more exposed to financial frictions will be more severely affected by uncertainty shocks. Hence, the aforementioned channels imply that uncertainty may affect firms in an heterogeneous way.

There is evidence that, ceteris paribus, firms in poorer financial condition and with a lower profitability profile may encounter more difficulties in accessing credit markets. Therefore, we expect the negative effect of uncertainty on corporate investment to be higher for firms with higher leverage and lower profitability. Notably, two effects may be in play. On the one hand, according to the bank lending channel, higher uncertainty will induce a credit supply shock that will affect firms asymmetrically: Firms in a

\footnotetext{
10 Bianco et al. (2013) show that family firms' investment is sensitive to firm-level uncertainty and relate this to the fact that family firms' owners may be more risk-averse as they hold large shares of wealth in the firm.
} 
weaker financial position will be more affected. On the other hand, a credit demand effect may also be in place. Firms in a weaker financial position may reduce their demand for credit relatively more than firms in a sound financial position when faced with uncertainty. This is compatible with the risk-aversion story.

Together with this, we expect that the negative effect of uncertainty on investment is greater for SMEs than for large firms. This may be related to the fact that the former face higher informational frictions, which may be relevant in determining growth opportunities but also in accessing financial markets. As long as informational frictions increase during periods of uncertainty, SMEs will be more affected. Together with this, as SMEs are more vulnerable to shocks, they may increase their aversion to risk when policy uncertainty is high. Thus, in this case, the three channels may affect SMEs to a greater degree.

Finally, if corporate groups are less affected by financial frictions, firms belonging to corporate groups may be less vulnerable to uncertainty shocks. The empirical literature highlights that while conglomerates may benefit from economies of scale in the access to credit and may exhibit lower risk of non-repayment (Inderst and Müller 2003; Faure-Grimaud and Inderst 2005; Kuppuswamy and Villalonga 2016; Yan et al. 2010), contagion effects due to idiosyncratic shocks among firms may prevail over coinsurance gains (Hege and Ambrus-lakatos 2002). In Appndix 6, we provide descriptive evidence that firms belonging to a corporate group enjoy a lower cost of debt (controlling for relevant firm-specific characteristics), and hence better credit conditions. Thus, since belonging to a corporate group may be related to lower financial frictions (ceteris paribus), the financial friction and risk-aversion channels would imply observing that these firms are less sensitive to economic policy uncertainty shocks. In Sect. 5.2, we explore these expectations by means of our heterogeneous effects analysis.

\section{Data}

We now describe the data used in the analysis. Section 3.1 describes the uncertainty measure we consider, while in Sect. 3.2 we outline the firm-level data used in the empirical exercise.

\subsection{The policy uncertainty measure}

To measure economic policy uncertainty, we borrow the EPU indicator for Spain constructed by Ghirelli et al. (2019), which is available online at the EPU website ${ }^{11}{ }^{12}$ This index is built following the methodology proposed by Baker et al. (2016), which

\footnotetext{
$11 \mathrm{https} / / / \mathrm{www} \cdot$ policyuncertainty.com/.

12 Uncertainty comprises two concepts: risk and Knightian uncertainty. Risk relates to situations where the outcome of an event is not known, but the probabilities of potential outcomes are, so that the odds of the event can be computed. With Knightian uncertainty, not only the outcome is unknown, but one also does not have the necessary information to compute the odds of potential outcomes. As common in this literature, our indicator of uncertainty encompasses both concepts and refrains from distinguishing between them.
} 


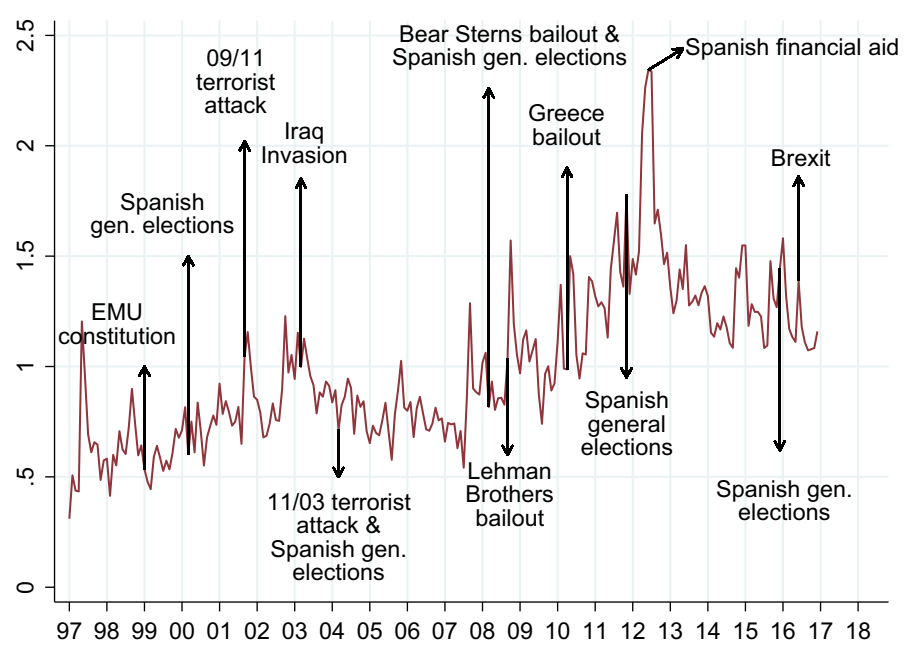

Fig. 1 Policy uncertainty index. This figure depicts the monthly EPU index for Spain that we borrow from Ghirelli et al. (2019) to carry out our analysis

is based on newspaper coverage frequency and is the most influential methodology to construct EPU measures. ${ }^{13}$

The Ghirelli et al.'s (2019) index is constructed as follows. First, it relies on articles published in 7 relevant Spanish national newspapers as from 1997 onwards: $E l$ País, El Mundo, La Vanguardia, ABC, Expansión,Cinco Días, and El Economista. Second, it is based on the number of articles containing simultaneously at least one keyword related to the categories of "uncertainty" (i.e., uncertain*, instab*, risk*), "economy" (i.e., economic, economy), and "policy" (i.e., Parliament, Moncloa, central government*, Hacienda, European Commission, deficit*, budget*, public expenditure*, public debt*, fiscal polic*, monetary polic*, tax*, European Central Bank, Bank of Spain, legislation*, reform*,norm*, regulation*, law*). Note the keywords are searched in Spanish language, taking care of singular/plural, masculine/feminine, and acronyms whenever needed. ${ }^{14}$ Third, the count of articles is scaled by the total number of articles in the same newspaper/month. Fourth, the monthly series of scaled counts are standardized to make them comparable across newspapers. Finally, the monthly index is computed as the average across the newspapers. ${ }^{15}$ The evolution of the EPU index is depicted in Fig 1.

The index increases when events occur that are generally considered to be related to higher economic policy uncertainty. For instance, the EPU indicator is high at the

\footnotetext{
13 Baker et al. (2016) constructed EPU indexes for the USA and for a number of other countries, including Spain. Ghirelli et al. (2019) used the same methodology improving the existing EPU index for Spain in three directions: (i) expanding the newspaper coverage, (ii) using a richer set of keywords, and (iii) covering a longer sample period [for more details, see Ghirelli et al. (2019)].

14 The asterisk means that any ending of the word is allowed for, i.e., the search query considers all words starting with a given root.

15 The original EPU index is also rescaled to mean 100. However, in our analysis we did not rescale the index for convenience.
} 


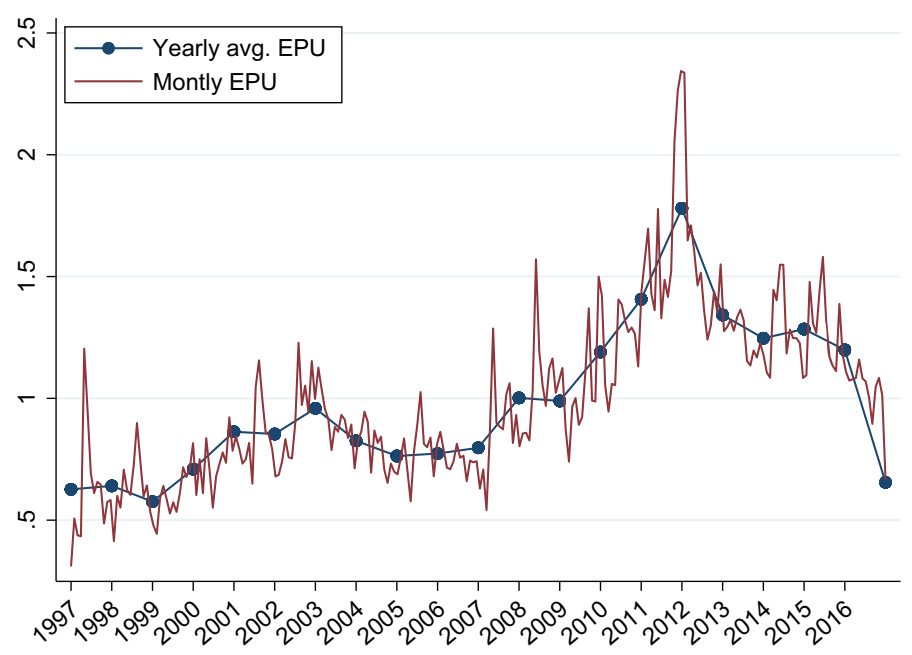

Fig. 2 Annual policy uncertainty index. This figure plots the original monthly EPU index against the annual average that we use in this analysis

time of the Greek bailout request in April 2010 and is highest during the Spanish request for financial aid in June 2012. It also picks when Brexit takes place. Another example may be periods just before general political elections. Electoral campaigns can increase uncertainty depending on agents' expectations about the outcome of the election and whether agents believe that the announced political stands will be followed coherently after the election. ${ }^{16}$ According to Fig. 1, the uncertainty about economic policy increased during the 2016 Spanish general electoral campaign.

Since we use yearly firm data, we aggregate the monthly series of uncertainty at the annual level. ${ }^{17}$ To do that, we take a standard average of monthly values for each calendar year, assigning equal weights to every month. In untabulated results, we show that our findings are robust to alternative definitions of the yearly index. In particular, we consider assigning increasing weights to later months. Since in our empirical analysis, the uncertainty indicator is lagged by one year, this means assuming that the uncertainty related to the later months of year $t-1$ is more likely to have an impact on firms' decisions in $t$ than the uncertainty related to the beginning of year $t-1$.

Figure 2 depicts the evolution of the yearly EPU index, showing our annual weighted average construction against the original monthly variation. The index shows an upward trend in the period of interest. As expected, economic policy uncertainty is countercyclical and as suggested by Bloom (2014), the measure may actually be reflecting economic conditions. A major challenge we face in our analysis is disentangling the effect of economic policy uncertainty from other aggregate time-varying

\footnotetext{
16 This is not necessarily the case and depends on the dispersion of citizens' expectations about future policies.

17 As explained in Sect. 3.2, firm data are available on an annual level. Despite we loose high-frequency variation in the uncertainty index, our sample allows us to explore the effect of uncertainty on SMEs firms.
} 
confounding factors (such as macroeconomic variables) that may explain investment. Our baseline analysis controls explicitly for the business cycle by including the GDP growth rate. In addition, in Sect. 6.1, we allow for alternative aggregate controls and discuss the robustness of the heterogeneous results by further controlling for time fixed effects. This latter approach helps us mitigate the concern of bias caused by aggregate factors that may be correlated with both uncertainty and investment decisions.

\subsection{Firm-level data}

We use firm data from the Integrated Central Balance Sheet Data Office Survey (CBI) of the Bank of Spain. This database includes data reported in the CBI Annual Survey by non-financial firms, as well as administrative data from the accounts filed with the mercantile registries. Overall, the CBI has a wide coverage of the Spanish nonfinancial sector, representing around 50\% of non-financial corporations in 2015 (Bank of Spain 2016). Firm data are available on an annual level.

Our analysis relies on an unbalanced panel of a representative sample of Spanish firms for the period 1998-2014. ${ }^{18}$ We apply standard cleaning procedures to firm data and consider firms that are observed at least twice in the period of study (1998-2014). Table 8 in Appendix A shows the panel structure of the data.

The final sample contains more than 3 million firm-year observations for a total of 616,740 firms. Table 7 in Appendix A compares the distribution of our sample to that of the population of Spanish firms for the period 1999-2014, as provided by the Central Directory of Firms (DIRCE). Overall, we observe a good representativeness of our final sample, although it is slightly underrepresentative of small firms, especially during the first years of the sample. Table 1 shows descriptive statistics for firm-level variables in the final sample. $1.3 \%$ of these are large firms, while all others are SMEs. On average, $3 \%$ of the firms are exporting firms and only $0.4 \%$ of firms belong to a corporate group. The gross investment-to-capital ratio is positive for $74 \%$ of observations in the sample, indicating that a large proportion of firm-year observations in the sample are characterized by investment (in gross terms). The average gross investment rate amounts to $13 \%$ with a standard deviation of about 26 percentage points $(p p)$. This suggests that the gross investment rate shows important variation in our data. This can also be seen in Fig. 3 in Appendix B, which shows the evolution of the average gross investment rate over time. Between 2007 and 2009, the average gross investment rate drops by about $7 \mathrm{pp}$ and maintains a lower level thereafter.

\section{Empirical strategy}

In order to identify the contribution of economic policy uncertainty to firms' investment decisions, we estimate static investment equations by means of panel regressions as in Gulen and Ion (2016) and Baker et al. (2016). Our baseline model is a classical

\footnotetext{
18 We cannot consider years before 1998 because our uncertainty index is available from 1997 and all regressors are lagged by one year. The time span ends in 2014 because we include information on exports, which is available until 2013. If we excluded export variables, we could extend the analysis to the period 1998-2016.
} 
Table 1 Descriptive statistics, full sample

\begin{tabular}{lrlrll}
\hline & Mean & Sd & Min & Max & N \\
\hline ROA & 0.049 & 0.170 & -1.676 & 0.721 & $3,318,739$ \\
Debt burden & 0.581 & 0.954 & 0.000 & 2.771 & $3,318,739$ \\
Debt rate & 0.693 & 0.454 & 0.000 & 4.830 & $3,318,739$ \\
Cash flow & -0.002 & 0.133 & -0.979 & 0.920 & $3,318,739$ \\
Sales growth & 0.050 & 0.534 & -1.000 & 10.289 & $3,318,739$ \\
SMEs & 0.987 & 0.114 & 0.000 & 1.000 & $3,318,739$ \\
Export & 0.030 & 0.172 & 0.000 & 1.000 & $3,318,739$ \\
Corp_group & 0.004 & 0.065 & 0.000 & 1.000 & $3,318,739$ \\
1(Gross Inv.> 0) & 0.738 & 0.440 & 0.000 & 1.000 & $3,318,739$ \\
Gross Inv.Rate & 0.130 & 0.255 & -1.594 & 2.143 & $3,318,739$ \\
\hline
\end{tabular}

investment equation of this type, augmented to control for both firm-specific investment predictors and macroeconomic conditions:

$$
(I / K)_{i t}=\alpha_{i}+\beta_{1} U_{t-1}+\boldsymbol{\beta}_{2}^{\top} \boldsymbol{X}_{i t-1}+\boldsymbol{\beta}_{3}^{\top} \boldsymbol{M}_{t-1}+\epsilon_{i t}
$$

Indexes $i$ and $t$ refer to the firm and the calendar year, respectively. $\alpha_{i}$ indicates firm fixed effects. The dependent variable is the gross investment rate, which is defined as gross fixed capital formation over total capital stock. All explanatory variables are lagged by one year in order to minimize endogeneity concerns. $\boldsymbol{X}$ is a vector of relevant firm-level characteristics explaining investment: We include variables that characterize the financial position of the firm (i.e., debt burden, debt rate, and cash flows), its profitability (ROA), future growth opportunities (i.e., sales growth), and other potentially relevant features, i.e., being a small or medium enterprise (SMEs), being an exporting firm (export), and belonging to a corporate group (corp_group). ${ }^{19}$ Our parameter of interest is the coefficient of the EPU indicator $(U)$. We lag it by one year because it takes time for investment decisions to materialize and we are interested in the causal effect of uncertainty. $\boldsymbol{M}$ is a vector of aggregate controls and possible confounders of our uncertainty proxy.

Finally, $\epsilon$ is the error term, which we cluster at the firm and year level by means of two-way clustering (Petersen 2009; Cameron et al. 2011). This enables us to simultaneously control for serial correlation (i.e., observations of the same firm may be correlated over time) and cross-sectional correlation (i.e., all firms are exposed to the same aggregate shocks each year). This allows us to keep the panel data structure unaltered and provide correct inference for our estimates (Petersen 2009).

\footnotetext{
19 We include SMEs, export, and corp_group in the baseline model since we are interested in the heterogeneous effects of policy uncertainty along these dimensions. However, the firm fixed effects model poorly estimates the coefficient of these variables due to their limited time variation. For this reason, the coefficients of these control variables are not reported. In contrast, the fixed effect model correctly estimates the interaction of these variables with the (time-varying) policy uncertainty index, which are reported and interpreted (see Sect. 6.1).
} 
Since we include firm fixed effects, everything that is constant in time and firmspecific is controlled for. Hence, the identification of the effects of firm-level factors relies on the variation of firm-level variables over time, i.e., variation with respect to the firm-specific mean in the observed period (within transformation). It must be noted that since uncertainty varies over time but does not vary along the cross section, we cannot include time fixed effects in our equation. If we did, time fixed effects would absorb all explanatory power of any aggregate time-varying variable, including our EPU measure.

The main challenge of our estimation strategy is to properly control for aggregate confounders of uncertainty. Given that investment opportunities and demand expectations are only partially proxied by firm-specific controls, investment decisions are expected to be correlated with the business cycle, which is itself correlated with residual investment opportunities and demand expectations. Furthermore, uncertainty may be negatively correlated with the business cycle and investment opportunities since policy makers often experience pressure to make policy changes during times of recession. Thus, the effect of uncertainty could be capturing the effect of poor investment opportunities (which are not controlled for by the explanatory variables and are therefore unobservable to the econometrician). In our baseline specification, we explicitly account for the business cycle by controlling for aggregate GDP growth rate. This indicator, which is available at an annual level from the Spanish Statistical Office's (INE) webpage, is meant to capture the aggregate dynamics of investment opportunities and expected demand. ${ }^{20}$ GDP growth rate and the EPU indicator show a pairwise correlation of -0.8 , i.e., they are highly linearly related. However, we check that such a correlation does not lead to problems of multicollinearity in our regression. ${ }^{21}$

The following section discusses the baseline results. Together with this, we analyze potential cross-sectional heterogeneity as well as the nonlinear relationship between uncertainty and investment. In Sect. 6.1, we discuss whether our baseline results are biased by the omission of other aggregate factors that may affect both policy uncertainty and corporate investment.

\section{Baseline results}

\subsection{The average effect of policy uncertainty}

We begin our empirical analysis by considering a classical investment panel regression with time fixed effects (column 1 of Table 2). Then, we drop time fixed effects in order to identify the direct effect of aggregate economic policy uncertainty on the investment ratio.

\footnotetext{
20 There exists many alternative proxies for the business cycle, such as unemployment rate and Economic Sentiment Indicator (ESI). Our results remain robust to individually including the mentioned variables.

21 We compute the variance inflation factors (VIF), which is the diagnostic used for collinearity. The average VIF for the baseline model is 1.5 , while the VIFs associated with the EPU indicator and GDP growth rate are both around 3. While there is no consensus on a VIF threshold indicating multicollinearity, $V I F>10$ are often considered alarming. Therefore, we believe that in our case, multicollinearity is of minor concern.
} 
Table 2 Baseline model: average effect of policy uncertainty

\begin{tabular}{|c|c|c|c|}
\hline & (1) & (2) & (3) \\
\hline \multirow[t]{2}{*}{$\mathrm{ROA}$} & $0.026 * * *$ & $0.053 * * *$ & $0.039 * * *$ \\
\hline & $(0.005)$ & $(0.006)$ & $(0.006)$ \\
\hline \multirow[t]{2}{*}{ Debt burden } & $-0.009 * * *$ & $-0.010 * * *$ & $-0.009 * * *$ \\
\hline & $(0.000)$ & $(0.001)$ & $(0.000)$ \\
\hline \multirow[t]{2}{*}{ Cash flow } & $0.065 * * *$ & $0.065 * * *$ & $0.067 * * *$ \\
\hline & $(0.003)$ & $(0.003)$ & $(0.003)$ \\
\hline \multirow[t]{2}{*}{ Debt rate } & $-0.036^{* * *}$ & $-0.019 * * *$ & $-0.026^{* * *}$ \\
\hline & $(0.004)$ & $(0.003)$ & $(0.003)$ \\
\hline \multirow[t]{2}{*}{ Sales growth rate } & $0.011 * * *$ & $0.015 * * *$ & $0.012 * * *$ \\
\hline & $(0.001)$ & $(0.002)$ & $(0.001)$ \\
\hline \multirow[t]{2}{*}{ SMEs } & $-0.011 * * *$ & $0.011 * *$ & 0.002 \\
\hline & $(0.003)$ & $(0.005)$ & $(0.005)$ \\
\hline \multirow[t]{2}{*}{ Export } & -0.002 & $-0.004 * *$ & $-0.004 * *$ \\
\hline & $(0.001)$ & $(0.001)$ & $(0.001)$ \\
\hline \multirow[t]{2}{*}{ corp_group } & $0.033 * * *$ & 0.009 & $0.021 * * *$ \\
\hline & $(0.005)$ & $(0.006)$ & $(0.004)$ \\
\hline \multirow[t]{2}{*}{ EPU } & & $-0.116^{* * *}$ & $-0.047 *$ \\
\hline & & $(0.025)$ & $(0.027)$ \\
\hline \multirow[t]{2}{*}{ GDP growth } & & & $0.007 * * *$ \\
\hline & & & $(0.001)$ \\
\hline Observations & 3318685 & 3318685 & 3318685 \\
\hline Adjusted $R^{2}$ & 0.154 & 0.141 & 0.146 \\
\hline
\end{tabular}

Note. This table reports results from estimating Eq. 1. The dependent variable is the investment rate. Firm FEs are accounted for by means of the within transformation. Standard errors are clustered at both the firm and year level through two-way clustering. In all regressions, the firm-level covariates are: debt burden, debt rate, cash flows, ROA, sales growth, SMEs, export, and corp_group (SMEs, export, and corp_group not reported). Column 1 includes time fixed effects (not reported), as opposed to all other columns. Column 2 includes the policy uncertainty indicator. Column 3 further includes GDP growth rate to the estimation in column 2

$*, * *, * * *$ Statistically significant at the $10 \%, 5 \%$, and $1 \%$ level, respectively

The first block of variables in Table 2 presents the role of traditional determinants of investment. No matter which specification is considered, these determinants appear to be significant and present the expected sign in accordance with the literature. Both the debt burden and the debt-to-asset ratio present a negative coefficient. This indicates that on average and ceteris paribus, being in a weaker financial position negatively affects the level of investment. In contrast, indicators of profitability such as the ROA ratio, and indicators related to future profitability such as sales and employment growth, present a positive coefficient. Thus, our results suggest that the financial and profitability position of a firm appears to affect the investment ratio, as suggested by the literature, which highlights the role of financial frictions in accessing external finance and in making investment decisions. 
In column 2 of Table 2, we drop time fixed effects in order to include the EPU index, which appears to negatively affect the investment ratio. However, as expected, the magnitude of this effect decreases when further controlling for the business cycle, reinforcing the above-mentioned need to control for potential confounders. ${ }^{22}$ As expected, lagged GDP growth, which is a proxy for investment opportunities, positively affects the investment rate.

According to our baseline specification (column 3), a one unit increase in the EPU index decreases the investment rate by $4.7 \mathrm{pp}$. To give a sense of this magnitude, several things are worth noting. First, as documented in Sect. 3.1, the EPU index ranges from 0.5 to 1.7 during the period 1998-2016. Hence, a one unit increase represents variation that is equivalent to episodes characterized by a significant increase in economic policy uncertainty. For example, such a sharp (monthly) increase in uncertainty is only seen in June 2012, when the Spanish government requested financial aid. Other particular uncertainty shocks, such as the Lehman Brothers bailout or Greece bailout, represent a variation of half a basis point, resulting in a decrease in the average investment rate of $2.3 \mathrm{pp}$, ceteris paribus.

Second, as illustrated in Fig. 3, the average investment rate has experienced fluctuations of considerable magnitude throughout the business cycle. In particular, we observe that during the financial crisis, investment decreased by about $7 \mathrm{pp}$. All in all, our estimation indicates that uncertainty has a sizable effect on investment, although other determinants are also behind the observed fluctuations in the investment ratio.

\subsection{Heterogeneous effects}

This section investigates the heterogeneous effects of economic policy uncertainty along a number of cross-sectional dimensions. In particular, we are interested to test whether it has differential effects for certain types of firms, or whether the effect of uncertainty is the same for all firms. In addition, to the extent that SMEs face informational frictions, they should be more vulnerable to changes in economic policy uncertainty than big firms. This may occur through worsening of credit conditions or increases in precautionary savings. Firms in a weaker financial position may find it more difficult to access credit markets. Hence, we expect them to be more exposed to uncertainty in case of credit tightening. Finally, exporters should be less sensitive to domestic uncertainty to the extent that they face external demand. Therefore, we expect the impact of the EPU index to be higher for non-exporting firms.

\footnotetext{
22 We expect the coefficient of policy uncertainty to be overestimated if the omitted variable is the business cycle. Consider a simplified linear model: $y=\alpha+\beta U+\gamma C+\epsilon$, where $U$ is policy uncertainty, $y$ is the investment rate, and $C$ is the business cycle. By assumption: $E(U \epsilon)=0$ and $E(C \epsilon)=0$; we expect $\beta<0$ and $\gamma>0$. Let $\operatorname{Cov}(U, C) \neq 0$. If $C$ is observed, $\beta$ and $\gamma$ are unbiased: $\beta=\operatorname{Cov}(U, y) / \operatorname{Var}(U)$, and $\gamma=\operatorname{Cov}(C, y) / \operatorname{Var}(C)$. If $C$ is omitted instead: $\beta=E(U, y) / E(U)^{2}=E(U, \beta U+\gamma C+\epsilon) / E(U)^{2}=$ $\beta+\gamma \times \operatorname{Cov}(U, C) / \operatorname{Var}(U)$. The estimator of $\beta$ is biased. The direction of the bias depends on the sign of the relationship between $C$ and $y(\gamma)$ and the correlation between $C$ and $U$. Since $\operatorname{Cov}(U, C)<0$ and $\gamma>0$, the overall bias is negative.
} 
To identify heterogeneous effects of uncertainty, the baseline specification becomes:

$$
(I / K)_{i t}=\alpha_{i}+\beta_{1} U_{t-1}+\boldsymbol{\beta}_{2}^{\top} \boldsymbol{X}_{i t-1}+\beta_{3} M_{t-1}+\beta_{4} U_{t-1} \times C_{i t-1}+\epsilon_{i t}
$$

where $M$ represents the GDP growth rate. $C$ is a firm-level control for which we compute the heterogeneous effect and which we interact with the EPU index. Note we compute one heterogeneous effect at a time for the following variables: a dummy that equals one if the $R O A$ is above the median, a dummy that equals one if debt rate is above the median, SMEs, export, and corp_group. Since these variables are all dummy variables, the coefficient $\beta_{1}$ represents the effect of the EPU index for the baseline group (i.e., the group of firms such that $C_{i t-1}=0$ ), while $\beta_{4}$ gives the differential effect of the EPU index for the other group (i.e., firms with $C_{i t-1}=1$ ).

Note that while the effects of constant or almost-constant firm-level characteristics are largely absorbed by the fixed effects, proper identification of the corresponding heterogeneous effects of economic policy uncertainty by these dimensions stems from the interaction of these variables with our EPU index, which varies over time (Wooldridge et al. 2001, Ch. 10.5).

In column 2, we look at the differential effect of uncertainty on investment rate for SMEs. We find a significant accentuation of the average negative effect for this group of firms, relative to larger ones. A one unit increase in the EPU index entails a decrease in the investment rate of less than one $p p$ (not significant) in the case of large firms, while the same change in the EPU index induces a $4.6 p p$ fall in the investment rate of SMEs. This finding suggests that there is important heterogeneity in the effect of uncertainty by firm size. According to the estimates, SMEs bear almost all of the burden of economic policy uncertainty. ${ }^{23}$

Significant heterogeneity is also found when looking at firms in poorer financial condition. For a one unit increase in the EPU index, the investment rate increases by $2.4 \mathrm{pp}$ for firms with a debt ratio above the median level. This finding may relate to the bank lending channel, which predicts that uncertainty shocks will asymmetrically affect firms that are not financially sound through an increase in the cost of debt and the tightening of access to credit.

Heterogeneous effects along the profitability dimension suggest that highly profitable firms (i.e., those with an ROA above the median value of the distribution) are slightly more affected than their counterparts. We interpret this result as follows. On the one hand, the effect of the EPU index on the investment decisions of profitable firms cannot be explained either by the risk-aversion channel (since, if anything, more vulnerable firms should be more negatively affected by an uncertainty shock), or by the financial frictions channel. In fact, if the latter is in place, we would expect more profitable firms to be less affected by an economic policy uncertainty shock, since they enjoy better access to credit and, as a consequence, can smooth the negative uncertainty shock if the investment is profitable. On the other hand, since the profitability of a firm relates not only to lower financial frictions but also to other factors such as higher

\footnotetext{
23 Note large firms comprise only $1.3 \%$ of our sample. We may not be able to detect a significant effect due to the small proportion of this type of firm. In any case, the estimate is consistent with the idea that large firms are less affected by policy uncertainty than SMEs, as expected.
} 


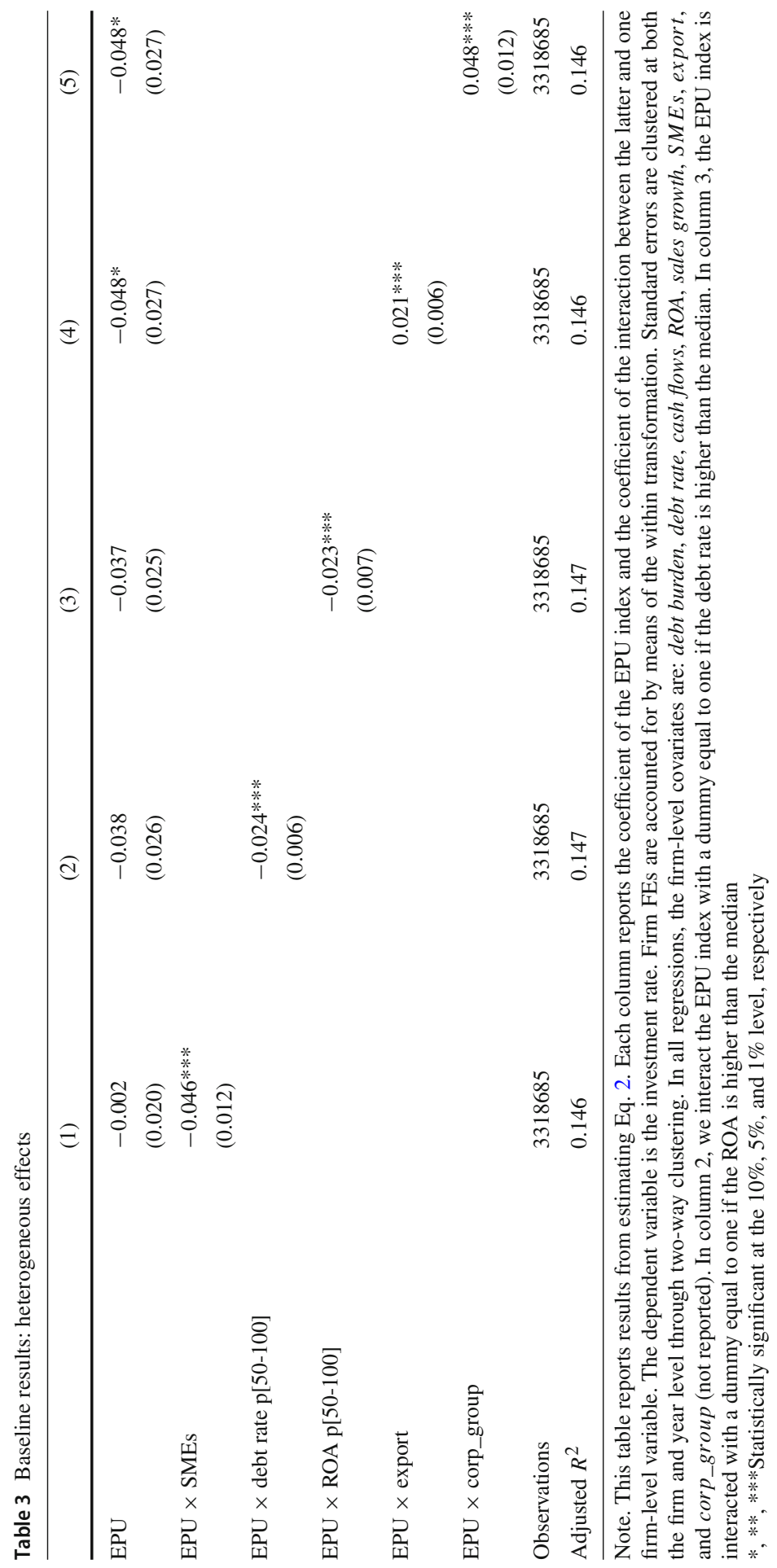


expected growth and investment opportunities, our estimate could be consistent with the wait-and-see channel. Firms with higher future growth opportunities may decide to delay (irreversible) investment projects in response to an increase in uncertainty. In other words, the greater ability of profitable firms to optimally adjust their investment levels may induce these firms to react to economic policy uncertainty by exercising the wait-and-see option.

Finally, we find significant differential effects for exporting firms and firms belonging to a corporate group. We observe that being an exporter firm reduces the average effect of a one unit increase in the EPU index on investment rate by about $2.1 \mathrm{pp}$, while the negative effect of uncertainty is further reduced up to $4.8 \mathrm{pp}$ for firms belonging to a corporate group. Thus, operating in external markets and belonging to a corporate group seem to partially alleviate the detrimental effects of higher uncertainty levels. On the one hand, the result for export can be rationalized by the fact that exporters are less sensitive to domestic policy uncertainty because they face an international demand. On the other hand, the role that corporate groups play in sheltering firms from uncertainty shocks may directly relate to the bank lending channel, to the extent that belonging to a corporate group facilitates access to credit. This should be particularly relevant for smaller firms, which face more financial frictions and have more difficulties in accessing credit.

All in all, our heterogeneous results are consistent with the hypotheses that economic policy-related uncertainty reduces corporate investment through increases in precautionary savings or to worsening of credit conditions. While the wait-and-see channel may play a relevant role in shaping investment decisions, our evidence suggests that the effect of uncertainty on investment decisions is further amplified by the financial frictions and risk-aversion channels.

\subsection{Nonlinear effects of uncertainty}

Column 2 of Table 11 (see Appendix D) extends our baseline specification with the inclusion of the second power of uncertainty. We attempt to capture potential nonlinear effects of uncertainty on the average investment ratio. Notably, our estimation yields significant coefficients for both the first and second power of uncertainty, being the former estimate positive and the latter negative. Thus, we uncover a U-shape relationship between uncertainty and investment. The (negative) marginal effect of uncertainty is attenuated toward zero the higher the level of uncertainty is. Hence, an identical shock to uncertainty will have different implications on investment depending on the initial level of uncertainty, being such effect weaker if the level of uncertainty is high.

In order to understand the economic relevance of the estimated effect, we perform three simple exercises. First, we employ our nonlinear specification to get a sense of the contribution of economic policy uncertainty on the evolution of the aggregate investment rate during the financial crisis (for details, see Appendix C). Results indicate that the increase in the EPU index between 2007 and 2010 would be accountable for roughly $35 \%$ of the $7 \mathrm{pp}$ fall in the average capital investment observed during this period. In this exercise, we maintain the uncertainty level of 2006 constant and look at the predicted investment ratio according to our estimation. In the year 2007, the 
actual average investment rate was $17 \%$. In 2010, the predicted average investment rate when fixing uncertainty at the 2006 level would have been $12.5 \%$ rather than the observed 10\%, remaining always above the observed level in the 2007-2010 period (see Fig. 4 in Appendix C). Thus, roughly $35 \%$ of the decrease in investment between 2007 and 2010 may be accounted for by the high levels of uncertainty following the financial turmoil of 2008.

Second, we inspect the implications of the nonlinear relationship between uncertainty and investment by plotting the marginal effect of a one unit increase in the EPU index against each decile of our index (see Fig. 5 in Appendix D). Given the documented U-shape relationship, the marginal effect gets attenuated toward zero the higher the level of uncertainty is. In particular, we find that the effect of a one unit increase in the EPU index ranges from $15 \mathrm{pp}$ for the lower deciles to roughly zero for the higher deciles.

Finally, we document how the linear and nonlinear specification differs regarding the predicted marginal effect on the investment rate. To do so, we focus on the period 2008-2014, characterized by large uncertainty shocks and a high level of economic policy uncertainty. Figure 6 in Sect. D. 1 depicts the predicted marginal effect of uncertainty on investment corresponding to the particular uncertainty variation in every year during this period. That is, if the EPU index raised by half a basis points from 2007 to 2008, we represent the marginal effect of uncertainty on investment associated with this half a basis point raise in the EPU index, for both the linear and nonlinear case. In this way, we can map particular well-known uncertainty shocks to their corresponding ceteris paribus effect on investment. As expected, we observe that the linear estimation overestimates the effect of uncertainty on investment when the level of uncertainty is high and underestimates it when the level of uncertainty is low. The sharp increase in uncertainty during June 2012 and the subsequent symmetric correction provides a case in point. While the linear estimation predicts a $2 \mathrm{pp}$ fall in investment and a subsequent symmetric positive impact on investment, the nonlinear specification predicts much more attenuated effects, both for the increase and decrease in the uncertainty level.

\section{Robustness analysis}

\subsection{The omitted bias problem}

The main challenge of our estimation strategy (Eq. 1) is to properly control for aggregate confounders of economic policy uncertainty. Investment decisions may be correlated with residual unobserved investment opportunities and demand expectations, to the extent that the latter are only partially proxied by firm-specific controls and the aggregate GDP growth rate. In this case, the effect of economic policy uncertainty could be capturing the effect of poor investment opportunities. Recall that we already control for future investment opportunities at the firm level by including sales growth rate, as is standard in the literature. This variable (like all other firm-level controls) is lagged by one year so as to minimize reverse causality concerns. However, 
the baseline specification may not properly control for relevant aggregate measures of investment opportunities that are not captured by the firm-level sales growth rate.

Aggregate measures of future investment opportunities are difficult to find and are highly correlated with the business cycle. As a robustness check, we additionally control for alternative business cycle indicators and a measure of future investment opportunities at the sector level, which we compute based on the Business and Consumer Surveys of the European Commission. We exploit questions asking firms about their expectations regarding future demand trends and compute a sector-specific measure of confidence about future demand. ${ }^{24}$ Results (see Table 12 in Appendix E) are robust to this procedure, and the coefficient of the sector-specific investment opportunities has a positive and significant effect. ${ }^{25}$ In any case, the correlation between this indicator and the firm-level sales growth rate aggregated at the sector level amounts to $77 \%$. Such a high correlation suggests that firm-level sales growth also appropriately controls for future investment opportunities at the sector level.

Ultimately, to minimize the possibility of bias, we would need to explicitly include in the model all relevant aggregate and time-varying confounders of the uncertaintyinvestment relationship. This is the empirical strategy followed by Gulen and Ion (2016). Possible candidates for aggregate factors that may affect firms' investment decisions are: measures of aggregate future growth opportunities; legislated corporate tax changes; and ${ }^{26}$ indicators about other relevant types of uncertainties (such as financial uncertainty or uncertainty about future aggregate demand). ${ }^{27}$ In Table 12 of Appendix E, we extend our baseline specification by controlling for financial and macroeconomic uncertainty for Spain, borrowing the two indexes developed by Gil et al. (2017). Our results prove to be robust, although the observed high VIF levels in some regressions suggest that multicollinearity may be a major caveat when extensively controlling for aggregate factors. Note that a another limitation of this strategy is that there is always the possibility that the list of aggregate control variables is not exhaustive. Therefore, the possibility of omitted variable bias remains.

In this section, we follow (Baker et al. 2016) and present the results of an additional exercise that allows us to overcome such limitations and provide additional evidence in favor of the channels through which the policy uncertainty effect materializes (heterogeneous effects). In particular, we modify Eq. 2 as follows: We include time fixed effects, drop the policy uncertainty variable, and maintain the interaction of the EPU

\footnotetext{
24 To minimize endogeneity concerns (respondents with optimistic expectations are more likely to invest and vice versa), we lag the indicator. Thus, we are explaining the investment rate in $t$ with the firm-level sales growth rate in $t-1$ (where the growth is computed by comparing the level in $t-1$ with the one in $t-2$ ) and the sector-level expectations about investment opportunities in $t-1$.

25 Note this measure has a drawback in that it is based on managers' evaluations (the survey asks whether they expect future demand to be normal, high, or low), which may depend on the cycle. For instance, the concept of "normal" demand may differ in upturns/downturns. This may bias the indicator.

26 They are relevant since investment decisions are shaped by fiscal policy and the timing of such policies may be correlated with the business cycle and policy uncertainty

27 Another stream of the literature underlines the role of firm-level uncertainty about future demand on investments: e.g., Guiso and Parigi (1999), Bontempi et al. (2010), Fuss and Vermeulen (2008), Bachmann et al. (2013), Leahy and Whited (1996), Bloom et al. (2007). This is not possible in our case, due to data availability.
} 
index with firm-level characteristics. This is formalized in Eq. 3:

$$
(I / K)_{i t}=\alpha_{i}+\boldsymbol{\beta}_{1}^{\top} \boldsymbol{X}_{i t-1}+\beta_{2} U_{t-1} \times C_{i t-1}+\phi_{t}+\epsilon_{i t}
$$

with $C$ being a firm-level control for which we compute the heterogeneous effect. As in the previous exercise, we compute one heterogeneous effect at a time for the following variables: A dummy equal to one if $R O A$ is above the median, and a dummy equal to one if debt rate is above the median, SMEs, export, and corp_group.

Note the time fixed effects $(\phi)$ absorb the effect of all factors that are common to the cross section and that vary over time. This means that we can no longer identify the effect of the EPU index as such (as well as the effect of the business cycle or the effect of any other aggregate control variable), because they are collinear with time fixed effects. However, we can identify the interaction between the EPU index and one specific firmlevel variable. This gives us a measure of the extent to which the investment rate of firms with specific characteristics covaries with policy uncertainty. Table 4 presents the differential effect of the EPU index for specific groups (the groups that are interacted with policy uncertainty) compared to the corresponding baseline groups. Note, in contrast to Eq. 2, when time fixed effects are included in the specification, one cannot compute the total effect of economic policy uncertainty by groups of firms, since the effect of the EPU index for the baseline groups is absorbed by the time fixed effects. ${ }^{28}$

The following comments are worth mentioning. First, the coefficients of the interactions in Table 4 are similar to those displayed in Table 3. The interaction with the SMEs and corporate group category is attenuated but still strongly significant. This suggests that introducing time fixed effects may effectively control for potential confounders. In addition to this, the fact that the differential effects are stable and significant across both specifications suggests that the results regarding heterogeneous effects are robust.

Second, the interaction with the debt rate remains negative and the interaction with the dummy for belonging to a corporate group remains positive. The former result suggests that the negative effect of debt rate on investment becomes larger during periods of higher uncertainty. ${ }^{29}$ In addition, belonging to a corporate group seems to shelter firms from the negative effect of economic policy uncertainty on investment. Hence, our estimations seem to corroborate the hypothesis that financial frictions, which are relevant in investment decisions, may be exacerbated during periods of high uncertainty.

Third, the negative interaction between the EPU index and SMEs is in line with the hypothesis that the latter may be more exposed to shocks in economic policy uncertainty, arguably due to informational frictions. By contrast, the interaction with profitability is not significant (although the sign remains negative). This offers weak evidence in favor of the hypothesis that the negative effect of uncertainty is stronger for firms with a better profitability profile.

\footnotetext{
28 The total effect of economic policy uncertainty for the group that is interacted with the EPU index is the sum of the differential effect (the coefficient of the interaction) and the effect of the EPU index for the baseline group (the coefficient of the EPU index itself). The latter is absorbed by the time fixed effects.

29 The coefficient of the debt rate is not shown in Table 4, but it is negative and significant.
} 


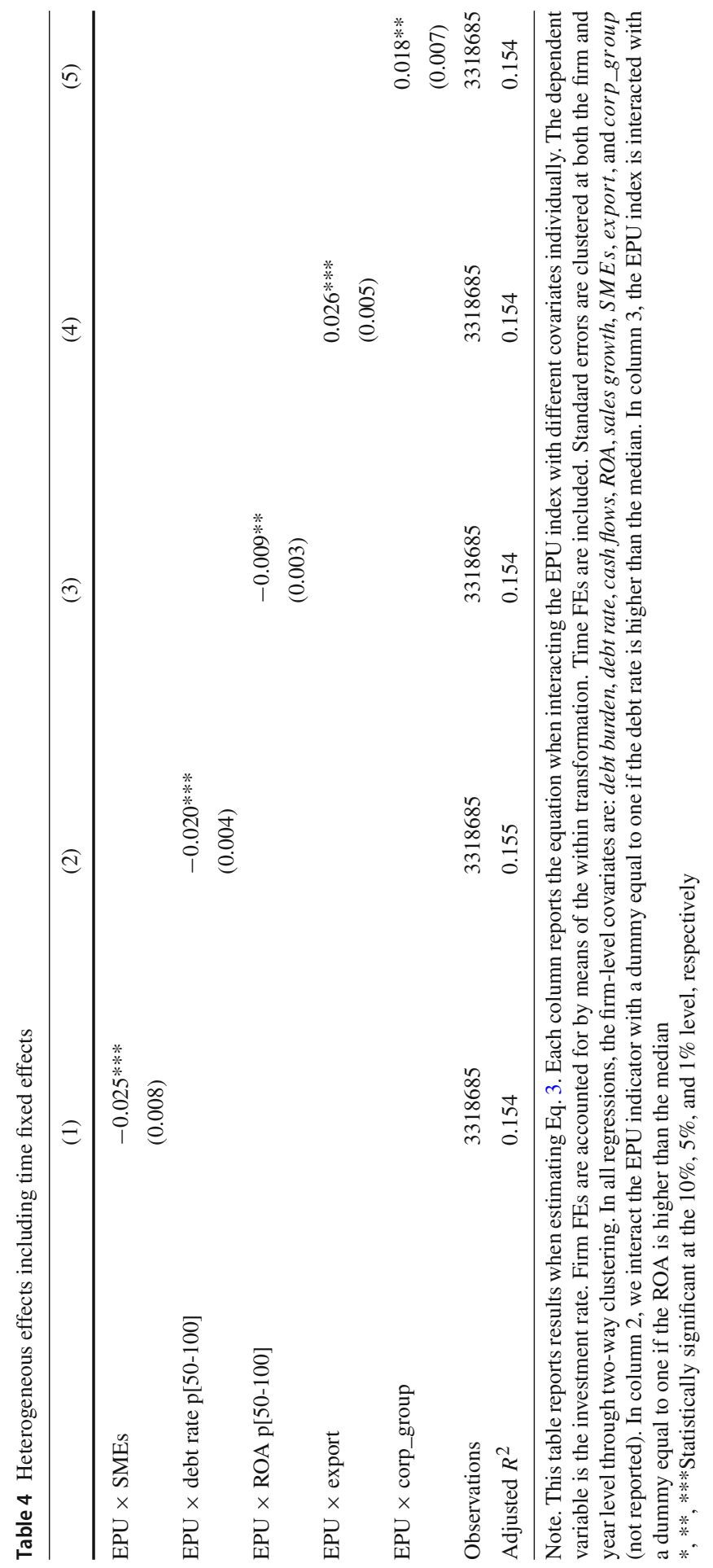


Finally, the interaction between the export dummy and the EPU index is positive and significant. This is also consistent with previous results: Exporting firms are less sensitive to policy uncertainty since they have access to foreign markets.

\subsection{Additional robustness checks}

We perform two additional robustness checks.

In a first exercise, we show that the results are robust when conditioned on strictly positive investment, that is, when we restrict the analysis to firms that decide to invest (in gross terms). Note that this restricted sample may be selective, which may prevent the making of inferences about the entire population. However, unconditional estimates might be biased if the dependent variable is not normally distributed. In our case, this might occur if there are a high number of observations with values of the dependent variable equal to zero. However, note that the gross investment rate is zero for $9 \%$ of observations. It can also be negative when firms decide to reduce capital and liquidate assets. This occurs for $18 \%$ of observations in our sample. Hence, we do not believe that the proportion of zeros in the dependent variable is a major concern. ${ }^{30}$ Results based on the subsample of observations with a strictly positive gross investment rate are reported in Tables 5 and 6 . The coefficients of interest are close to those estimated for the entire sample (unconditional estimates).

As a last robustness check, we consider the dynamic version of the baseline model, in which the lagged dependent variable is included as additional regressor on the righthand side of the empirical specification. On the one hand, it is appealing to consider a dynamic investment equation since it allows to model a partial adjustment mechanism in investment decisions. ${ }^{31}$ On the other hand, from an empirical point of view, adding the lagged values of the dependent variable on the right-hand side of the equation introduces an endogeneity problem. This is because the within or first difference transformation needed to drop firm fixed effects introduces a negative correlation between the transformed residuals and the transformed lagged dependent variable. As a consequence, the estimate of the lagged dependent variable is biased downwards. In addition, the estimated coefficients of the other regressors may be biased as well to the extent that they are correlated with the lagged dependent variable. One way to tackle this problem is to rely on the Generalized Methods of Moments (GMM), where the lagged values of the regressors are used as instruments for the (endogenous) variables. Of course, as any instrumental variable approach, GMM estimations rely on the validity of the chosen instruments, namely relevance and exogeneity. In particular, the latter, known as the exclusion restriction, implies that the assumptions should be assessed on a case by case basis.

\footnotetext{
30 In addition, since the fixed effects model exploits within-firm time variation, we might also be concerned about the loss of observations with no variability in the observed period. However, this is only the case for $2 \%$ of the firms in our sample.

31 From a theoretical point of view, smoothing investment over time is rationalized by convex adjustment costs. A static investment model is equivalent of ignoring adjustment costs of capital (or assuming linear adjustment costs). That is, in each period the firm observes the shock and chooses tomorrow's optimal capital stock regardless of the current value of the capital stock.
} 


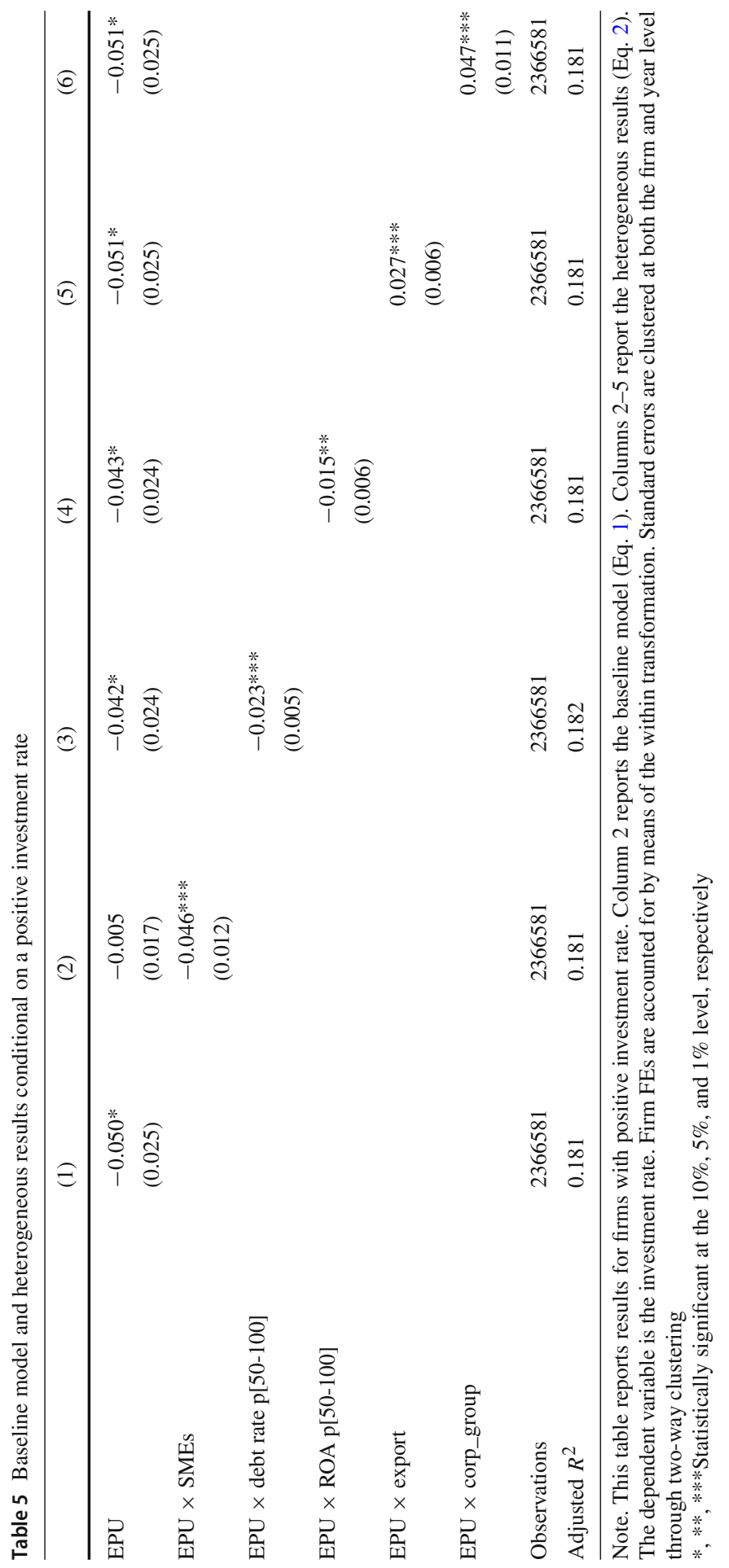


Table 6 Heterogeneous results with time fixed effects conditional on a positive investment rate

\begin{tabular}{|c|c|c|c|c|c|}
\hline & (1) & (2) & (3) & (4) & (5) \\
\hline EPU $\times$ SMEs & $\begin{array}{l}-0.026 \text { *** } \\
(0.008)\end{array}$ & & & & \\
\hline EPU $\times$ debt rate $p[50-100]$ & & $\begin{array}{l}-0.017 * * * \\
(0.004)\end{array}$ & & & \\
\hline $\mathrm{EPU} \times \mathrm{ROA} p[50-100]$ & & & $\begin{array}{l}-0.002 \\
(0.003)\end{array}$ & & \\
\hline $\mathrm{EPU} \times$ export & & & & $\begin{array}{l}0.029 * * * \\
(0.005)\end{array}$ & \\
\hline EPU $\times$ corp_group & & & & & $\begin{array}{l}0.015^{* *} \\
(0.006)\end{array}$ \\
\hline Observations & 2366581 & 2366581 & 2366581 & 2366581 & 2366581 \\
\hline Adjusted $R^{2}$ & 0.189 & 0.190 & 0.189 & 0.189 & 0.189 \\
\hline
\end{tabular}

Note. This table reports results when estimating Eq. 3 for firms with positive investment rate. Each column reports the equation when interacting the EPU index with different covariates individually. The dependent variable is the investment rate. Firm FEs are accounted for by means of the within transformation. Time FEs are included. Standard errors are clustered at both the firm and year level through two-way clustering $*, * *, * *$ Statistically significant at the $10 \%, 5 \%$, and $1 \%$ level, respectively

For instance, in the difference GMM estimator (Arellano and Bond 1991), the model is transformed in first differences, and the lagged values of the regressors in level are used as instruments. The identifying assumption is that lagged values of variables are independent from future shocks. This is reasonable, unless one does not argue that firms anticipate future shocks and change their behavior accordingly. In addition, a limit of the difference GMM is that for highly persistent variables, the lagged values of the variables in level may be poor instruments for their first difference transformation.

An alternative is the system GMM (Arellano and Bover 1995; Blundell and Bond 1998), which augments the difference GMM with an equation in level and uses lagged differenced variables as instruments for the variables in level. The additional assumption is that lagged changes in the variables should be independent from firm fixed effects and future shocks. This implies that the variables are mean stationary, i.e., firms of given type perform around their steady state in the period of observation. This may be correct for mature firms, but harder to assume for young firms which do not have yet reached their steady state level. In this case, changes in the past values of the variables may be related to their firm type.

In our case, the debt rate variable is very persistent (with a serial correlation coefficient of 0.9 ), while the profitability and the debt burden show a serial correlation coefficient of 0.47 and 0.45 , respectively. Hence, using the lagged levels of these variables as instruments in the difference GMM may not be desirable. As for using lagged differenced variables as instruments in the level equation, this relies on the assumption that the variables are mean stationary. In our case, this may not hold since our observation period includes the Great Recession which may have induced a structural break in certain variables. 
We estimate the dynamic equation using a GMM approach, but the obtained results are questionable, for the reasons illustrated above. The tests for the validity of the instruments (the Hansen test of over-identifying restrictions and the second order serial correlation test) lead us to reject the null hypothesis that the instruments are valid. As a consequence, we refrain to use a dynamic specification and rather maintain the static one as the main model, which provides a cleaner setting to identify the coefficient of the economic policy uncertainty on firms' investment decision. In addition, this choice allows us to compare the findings with those by Gulen and Ion (2016) and Baker et al. (2016), which adopt the same empirical strategy.

\section{Conclusion}

This study exploits firm-level panel data to study the impact of economic policy uncertainty on corporate investment in Spain. We focus on the average effect of the EPU index on the gross investment-to-capital ratio, as well as its heterogeneous effects along a set of firm-specific controls that may be related to different channels for the effect of uncertainty. In order to measure the aggregate level of economic policy uncertainty in the Spanish economy, we rely on the policy uncertainty indicator constructed by Ghirelli et al. (2019). This index follows the methodology proposed by Baker et al. (2016), which is based on newspaper coverage frequency.

The baseline model controls for the business cycle and aggregate demand by including the aggregate GDP growth rate. This specification allows us to identify the average effect of economic policy uncertainty on the investment rate, potential nonlinear effects of uncertainty as well as heterogeneous effects according to firm characteristics. As a robustness exercise, we include alternative aggregate controls and replicate the heterogeneous results by further including time fixed effects. In this way, we control for any aggregate time-varying factor affecting all firms over time. This minimizes the problem of omitted variable bias in estimating the heterogeneous effects of policy uncertainty. This robustness exercise suggests that our heterogeneous results, as well as the estimated coefficient of the effect of economic policy uncertainty in the baseline model, are not biased by omitted aggregate factors.

The existing literature documents the adverse effect of economic policy uncertainty on the investment decisions of publicly listed firms in the USA. This paper provides similar evidence for a representative sample of Spanish firms, most of which are SMEs and not quoted on the Spanish stock exchange. We find strong evidence that policy uncertainty reduces the rate of corporate investment in Spain. According to our baseline specification, a one unit increase in the EPU index decreases the average investment rate by about $4.7 \mathrm{pp}$. Furthermore, we uncover that the relationship between uncertainty and investment is nonlinear, being the marginal effect of a one unit increase in uncertainty attenuated toward zero the higher the level of uncertainty is. To give a sense of the magnitude of the effect of uncertainty, we estimate that the increase in economic policy uncertainty between 2007 and 2010 may be accountable for roughly one-third of the $7 \mathrm{pp}$ fall in the capital investment rate observed during this period.

The heterogeneous results indicate that the adverse effect of policy uncertainty is particularly relevant for highly vulnerable firms. Specifically, exporting firms are 
less affected by policy uncertainty than non-exporting ones, presumably because they operate in foreign markets and are therefore less exposed to policy uncertainty. SMEs and highly indebted firms decrease investment significantly more than their counterparts. In addition, firms belonging to a corporate group are less affected by economic policy uncertainty shocks. To the extent that belonging to a corporate group facilitates access to banking finance, these results are consistent with the hypothesis that firms in a weaker financial position are more sensitive to policy uncertainty shocks than their counterparts. This is in line with the idea that part of the explanation for the negative relationship between economic policy uncertainty and corporate investment is the financial frictions channel, according to which the credit supply shrinks when uncertainty is high and this reduces investment spending. This channel may be particularly relevant in the Spanish context, since corporate investment is largely financed by bank lending. Our results are also compatible with the risk-aversion channel, according to which firms may become more risk-averse during periods of high economic policy uncertainty and hence reduce investment.

Ultimately, our findings have the following implication: investing firms like predictability, and since corporate investment is a key driver of the growth of the economy in the long term, economic policy uncertainty should be minimized. While some degree of policy uncertainty is intrinsic to the democratic game and cannot be avoided, it could be certainly minimized if policy makers, politicians, and institutions stick to credible announcements and consistent behavior. Such an environment would set favorable conditions for economic agents to engage in investment projects. In other words, not only does the content of implemented policies have real effects, but the way in which policies are brought forward also shapes the decisions of economic agents.

\section{Declarations}

Conflict of interest The authors declare that they do not have conflict of interests.

Ethical approval This article does not contain any studies with human participants or animals performed by any of the authors.

Open Access This article is licensed under a Creative Commons Attribution 4.0 International License, which permits use, sharing, adaptation, distribution and reproduction in any medium or format, as long as you give appropriate credit to the original author(s) and the source, provide a link to the Creative Commons licence, and indicate if changes were made. The images or other third party material in this article are included in the article's Creative Commons licence, unless indicated otherwise in a credit line to the material. If material is not included in the article's Creative Commons licence and your intended use is not permitted by statutory regulation or exceeds the permitted use, you will need to obtain permission directly from the copyright holder. To view a copy of this licence, visit http://creativecommons.org/licenses/by/4.0/.

\section{Appendix}

\section{A Firm data appendix}

\section{Data cleaning}


- We replace negative values with missing ones in the following variables: fixed tangible capital stock, fixed intangible capital stock, net capital amortization.

- We drop observations with zero or missing sales for two consecutive years or with zero or missing employment for two consecutive years if the firm operates in the construction or housing sectors.

- We exclude holdings.

- We drop observations with negative values in debt, total assets, sales, or fixed capital.

- We drop observations where the current value of sales is positive, but the lagged value of sales is zero.

- We drop observations with missing values in at least one of the following variables: investment rate, debt burden, debt rate, sales growth rate, cash flow, and size.

- We remove outliers by dropping observations with values lying in the 1st or 99th percentile of the distribution of relevant variables (dependent or explanatory variables).

- We restrict the sample of analysis to non-financial firms which are observed in the CBI for at least two years. The structure of the panel is reported in Tables 7 and 8.

\section{Variables definition}

- Debt burden: interest payments plus financial costs divided by gross operating revenue plus gross financial revenue.

- Profitability (ROA): sum of gross operating revenue plus gross financial revenue minus financial costs and interest payments, divided by total assets.

- Debt ratio: total outstanding debt minus cash and its equivalents, divided by total assets.

- Cash flows: change in cash holdings relative to the previous year divided by total assets.

- Total capital stock: sum of fixed tangible capital stock (including real estate investment) and fixed intangible capital stock.

- Gross investment rate: the sum of gross fixed tangible and intangible capital formation, divided by the total capital stock.

- Sales growth rate (at firm level): computed with respect to the previous year. The variable takes a value of zero if firm sales are zero in two subsequent years.

- SME dummy: equal to one if the firm is an SME and zero otherwise. SME is based on the definition of the European Commission (2003/361/CE): SMEs are firms with fewer than 250 employees and fewer than 50 million euros of turnover or firms for which the total balance sheet is lower than 43 million euros. The SME dummy variable takes a value of one if the firm fulfills these conditions and zero otherwise.

- Corporative group dummy: equal to one if the firm belongs to a corporate group, zero otherwise.

- Exporter dummy: This variable is derived from the Spanish Balance of Payments micro-dataset. The dataset includes all firms that have exported with transaction values above 50,000 euros. 


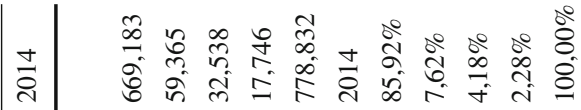

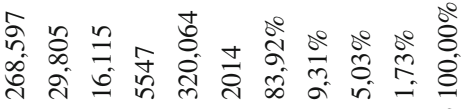

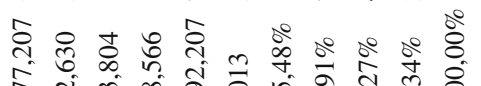

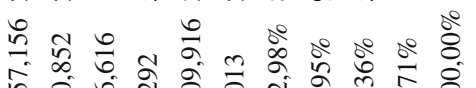

等

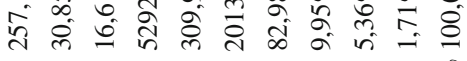

等

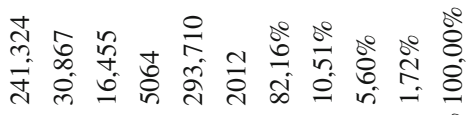

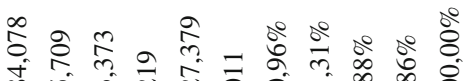

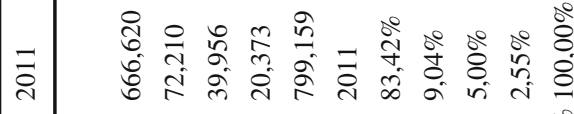

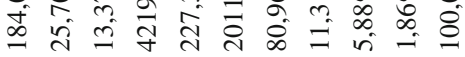

言等

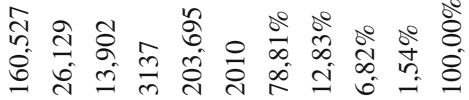

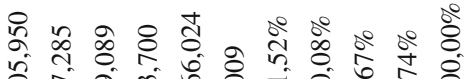

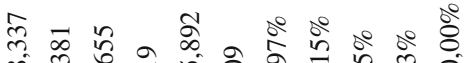

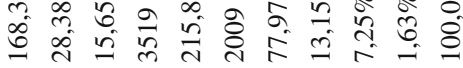

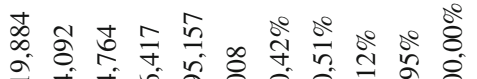

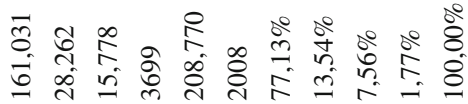

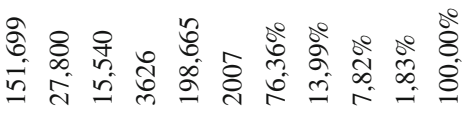

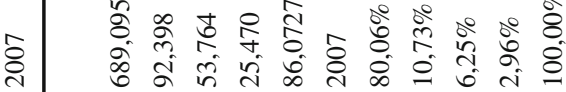

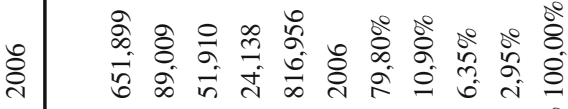

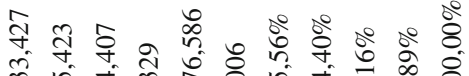

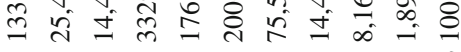

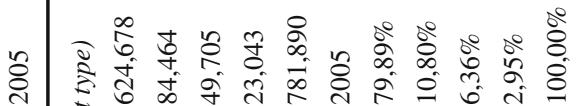

再 융

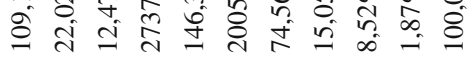

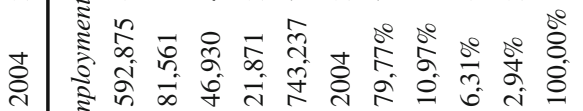

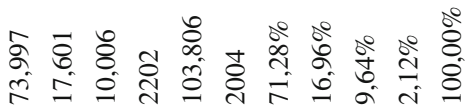

व

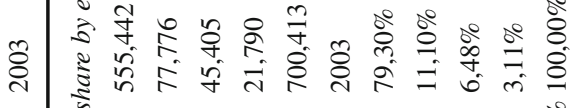

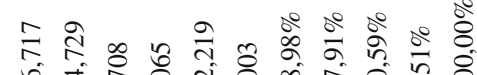

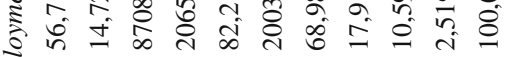

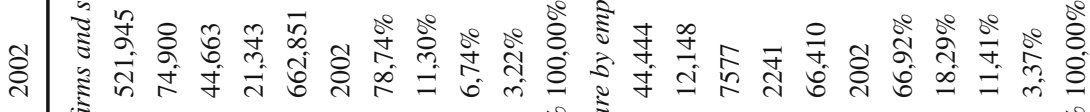

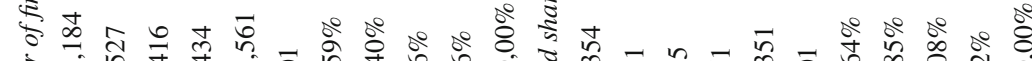

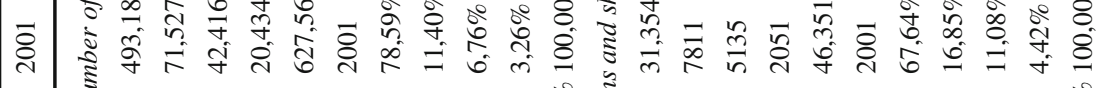
है

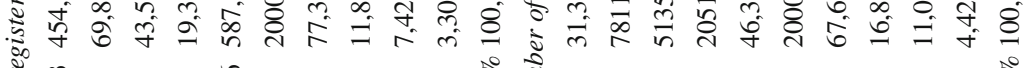

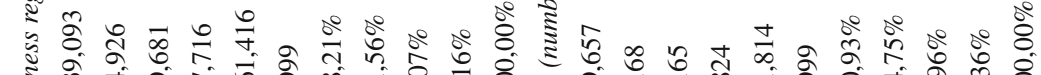

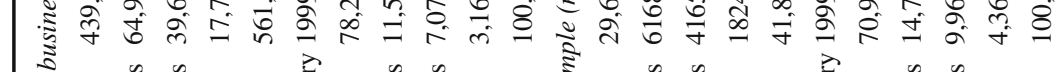

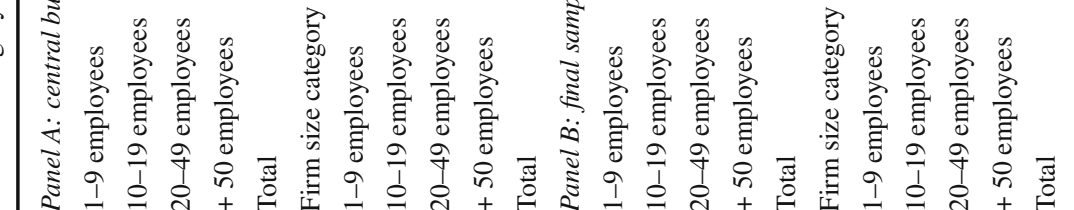




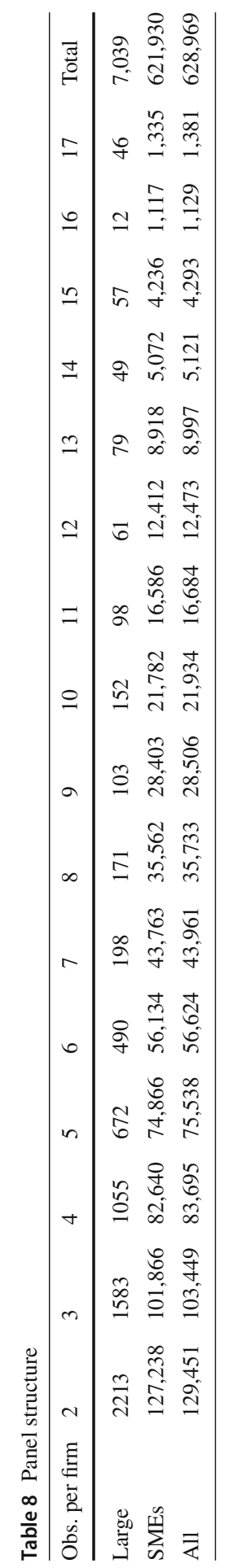




\section{B Descriptive statistics}

See Fig. 3, Tables 9 and 10.

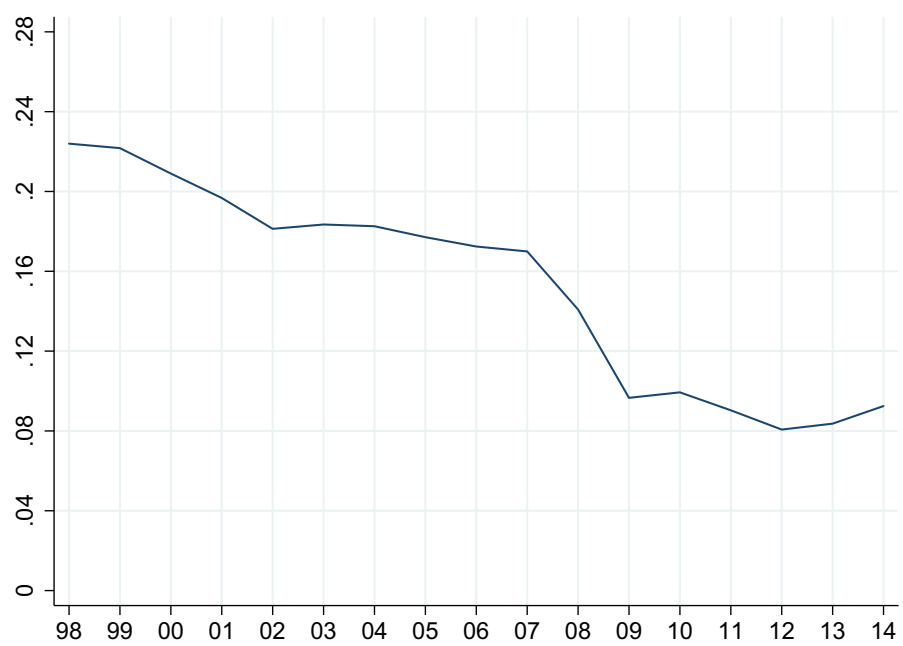

Fig. 3 Average gross investment rate in the sample

Table 9 Means by export status

\begin{tabular}{llllr}
\hline & Not exporters & Exporters & Diff. in Means & Pval \\
\hline ROA & 0.048 & 0.085 & -0.038 & 0.000 \\
Debt burden & 0.587 & 0.394 & 0.193 & 0.000 \\
Debt rate & 0.696 & 0.601 & 0.095 & 0.000 \\
Cash flow & -0.002 & 0.005 & -0.007 & 0.000 \\
Sales growth & 0.049 & 0.072 & -0.023 & 0.000 \\
SMEs & 0.991 & 0.871 & 0.119 & 0.000 \\
Export & 0.000 & 1.000 & -1.000 &. \\
Corp group & 0.002 & 0.075 & -0.073 & 0.000 \\
$\mathbb{1}$ (Gross Inv. $>0)$ & 0.734 & 0.871 & -0.137 & 0.000 \\
Gross Inv.Rate & 0.129 & 0.170 & -0.042 & 0.000 \\
N.Obs. & $3,217,536$ & 101,203 & &
\end{tabular}


Table 10 Means by being part of corporate group status

\begin{tabular}{lllll}
\hline & Not part of corp_group & Part of corp_group & Diff. in Means & Pval \\
\hline ROA & 0.049 & 0.085 & -0.037 & 0.000 \\
Debt burden & 0.582 & 0.397 & 0.185 & 0.000 \\
Debt rate & 0.694 & 0.577 & 0.116 & 0.000 \\
Cash flow & -0.002 & -0.000 & -0.001 & 0.196 \\
Sales growth & 0.050 & 0.026 & 0.023 & 0.000 \\
SMEs & 0.990 & 0.304 & 0.685 & 0.000 \\
Export & 0.028 & 0.534 & -0.506 & 0.000 \\
Corp_group & 0.000 & 1.000 & -1.000 &. \\
$\mathbb{1}$ (Gross Inv.> 0) & 0.738 & 0.892 & -0.154 & 0.000 \\
Gross Inv.Rate & 0.130 & 0.146 & -0.016 & 0.000 \\
N.Obs. & $3,304,558$ & 14,181 & & \\
\hline
\end{tabular}

\section{The role of policy uncertainty on the investment rate}

In this section, we run an exercise to get a sense of the magnitude of the direct contribution of economic policy uncertainty to the evolution of the aggregate investment rate in the country. To do this, we compute the evolution of the average gross investment rate in the simulated situation in which the EPU index is fixed at the value attained in 2006 for the period 2007-2014. Results are depicted in Fig. 4. The black line represents the evolution of the actual average investment-to-capital ratio. The chart shows a sharp decline in investment from 2008, with a mild recovery starting in 2013 . The dashed blue line depicts the average predicted evolution of the investment rate based on our baseline model and is constructed in two steps. First, we estimate Eq. 1 and obtain the predicted values for the investment ratio. Second, we obtain yearly averages for this estimate. Finally, the dashed red line refers to the average predicted values for the investment rate mimicking the previous aggregate until 2006, whereas afterward, we assume the uncertainty level to remain fixed at the year 2006 level.

Note that this exercise allows to get an idea of the direct effect of uncertainty on investment during the crisis. This is because we set uncertainty at the pre-crisis level but leave unchanged the other regressors. In this sense, we provide a lower bound of the impact of uncertainty. 


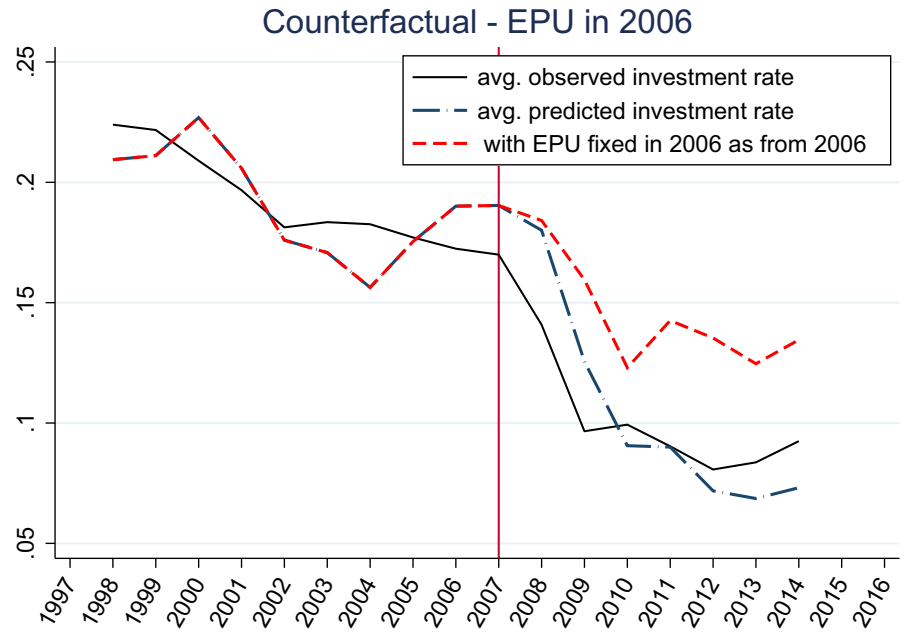

Fig. 4 Predicted gross investment rate if the EPU index remains fixed at the level attained in 2006 from 2007 onwards

\section{The nonlinear effect of economic policy uncertainty}

See Figure 5 and Table 11.

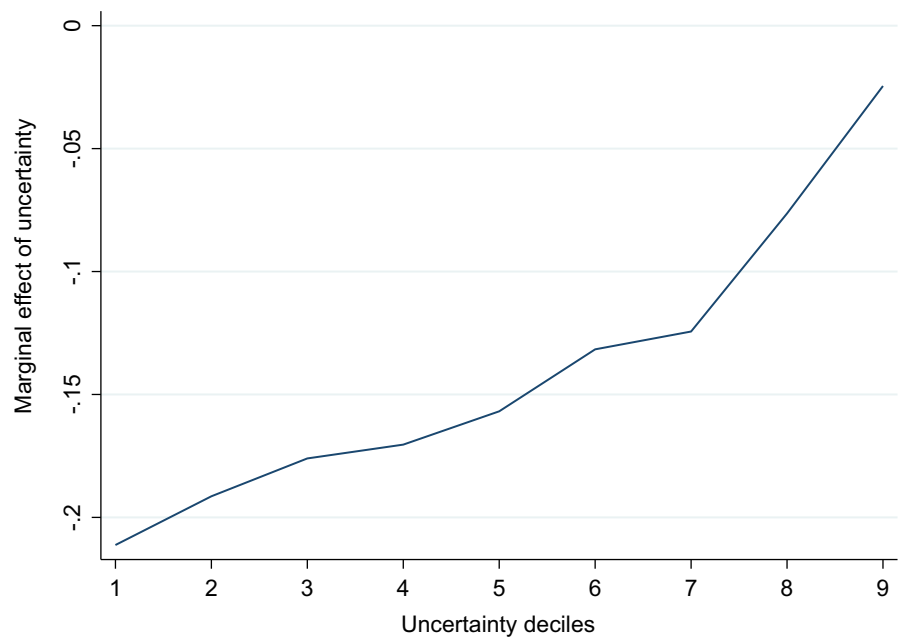

Fig. 5 Marginal effect of the EPU index on investment by decile of EPU 
Table 11 Nonlinear average effect of policy uncertainty

\begin{tabular}{lll}
\hline & $(1)$ & $(2)$ \\
\hline EPU & $-0.047^{*}$ & $-0.361 * * *$ \\
& $(0.027)$ & $(0.084)$ \\
GDP growth & $0.007 * * *$ & $0.005 * * *$ \\
& $(0.001)$ & $(0.001)$ \\
EPU $\times$ EPU & & $0.120^{* * *}$ \\
Observations & & $(0.029)$ \\
Adjusted $R^{2}$ & 3318685 & 3318685 \\
\hline
\end{tabular}

This table reports results from estimating Eq. 1. The dependent variable is the investment rate. Firm FEs are accounted for by means of the within transformation. Standard errors are clustered at both the firm and year level through two-way clustering. In the regressions, the untabulated firm-level covariates are: debt burden, debt rate, cash flows, ROA, sales growth, SMEs, export, and corp_group (SMEs, export, and corp_group not reported). Both the magnitude of the associated coefficient and significance are stable in the two specifications. Column 1 includes the policy uncertainty indicator while controlling for GDP growth. Column 2 further introduces the interaction $E P U \times E P U$, allowing for the marginal effect of uncertainty to be nonlinear $*, * *, * * *$ Statistically significant at the $10 \%, 5 \%$, and $1 \%$ level, respectively

\section{D.1 Comparison of linear and nonlinear marginal effect}

In this exercise, we attempt to illustrate the linear and nonlinear marginal effect of the EPU index on investment focusing on the period 2008-2014. This period is characterized by relevant uncertainty shocks and a high level of uncertainty. Given our empirical specification for $(I / K)_{i t}$ in Eq. 1, we estimate the marginal effect associated with the annual change in uncertainty $\Delta U_{t}=U_{t}-U_{t-1}$ as:

$$
\text { MarginalEffect }_{\Delta U}=\frac{\partial \mathbf{E}(I / K)_{i t}}{\partial U_{t}} \times \Delta U_{t}
$$

We repeat the exercise considering the nonlinear specification (column 2 of Table 11). Notably, the marginal effect will now depend on the level of uncertainty. As an approximation to the particular level of uncertainty at which the marginal effect is considered (given the significant within year fluctuations in uncertainty), we take the average of the current, one-year and two-year lagged uncertainty. Alternative approaches may slightly affect the estimated magnitude of the marginal effects but not the qualitative behavior of the linear and nonlinear model, which we attempt to emphasize in this exercise (Fig.6). 


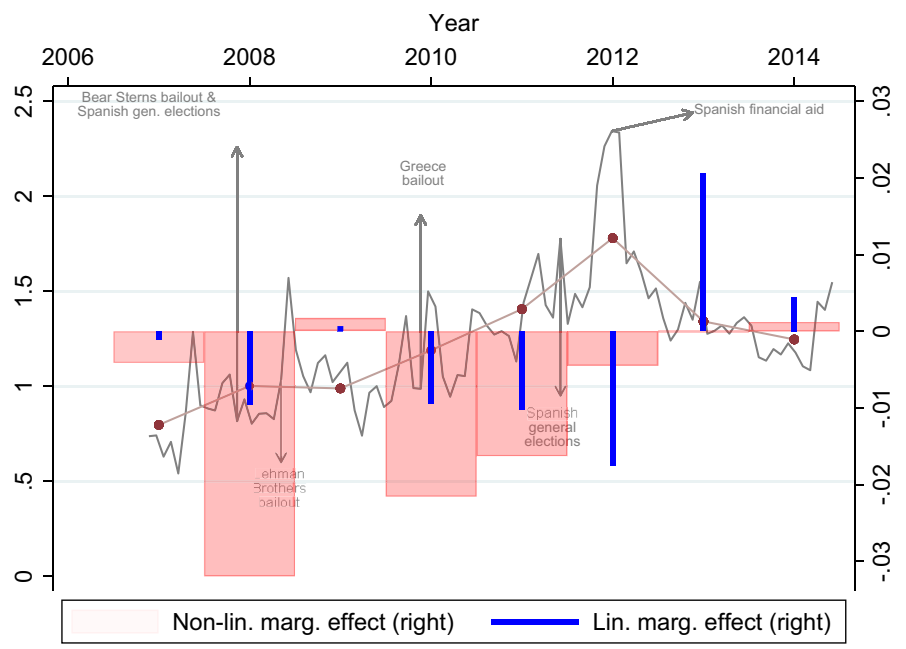

Fig. 6 Evolution of the EPU index and linear and nonlinear marginal effects associated with the particular annual variation of the EPU index

\section{E Aggregate controls}

\section{See Table 12.}

As a robustness check, we estimate the model by replacing the aggregate GDP growth rate with alternative macro-controls. Together with this, we include potential confounders of the economic policy uncertainty and investment relationship.

We first assess the impact of including the sector-specific gross value added (GVA) growth rate. ${ }^{32}$ When sector-specific GVA growth rate is included in the model, results are very similar to those we obtain when controlling for the GDP growth rate. The parameter in front of the GVA growth rate is positive and significant, while the effect of economic policy uncertainty remains negative and significant, amounting to -0.04 , a slightly higher value than in the baseline model. As expected, this suggests that the sector-specific GVA growth rate may not capture the business cycle as fully as the GDP growth rate. As a consequence, the economic policy uncertainty estimator is slightly overestimated.

We next consider the impact of including the interest rate ${ }^{33}$. It appears to have a negative effect on investment, although not significant when simultaneously including GDP growth in the regression. The ESI index (Economic Sentiment Indicator) is

\footnotetext{
32 The GVA growth rate shows higher variation than the GDP growth rate since the time variation faced by firms is sector-specific. However, it relies on the hypothesis that firms are only affected by the business cycle of the sectors in which they operate, and that they are not affected by the business cycles of other sectors. This ignores across-sectors spillover effects. By contrast, including the aggregate GDP growth rate implies assuming that all firms face the same business cycle, regardless of the sector in which they operate, which seems more reasonable.

33 Interest Rates, discount rate for Euro Area (INTDSREZM193N). Retrieved from https://fred.stlouisfed. org/series
} 


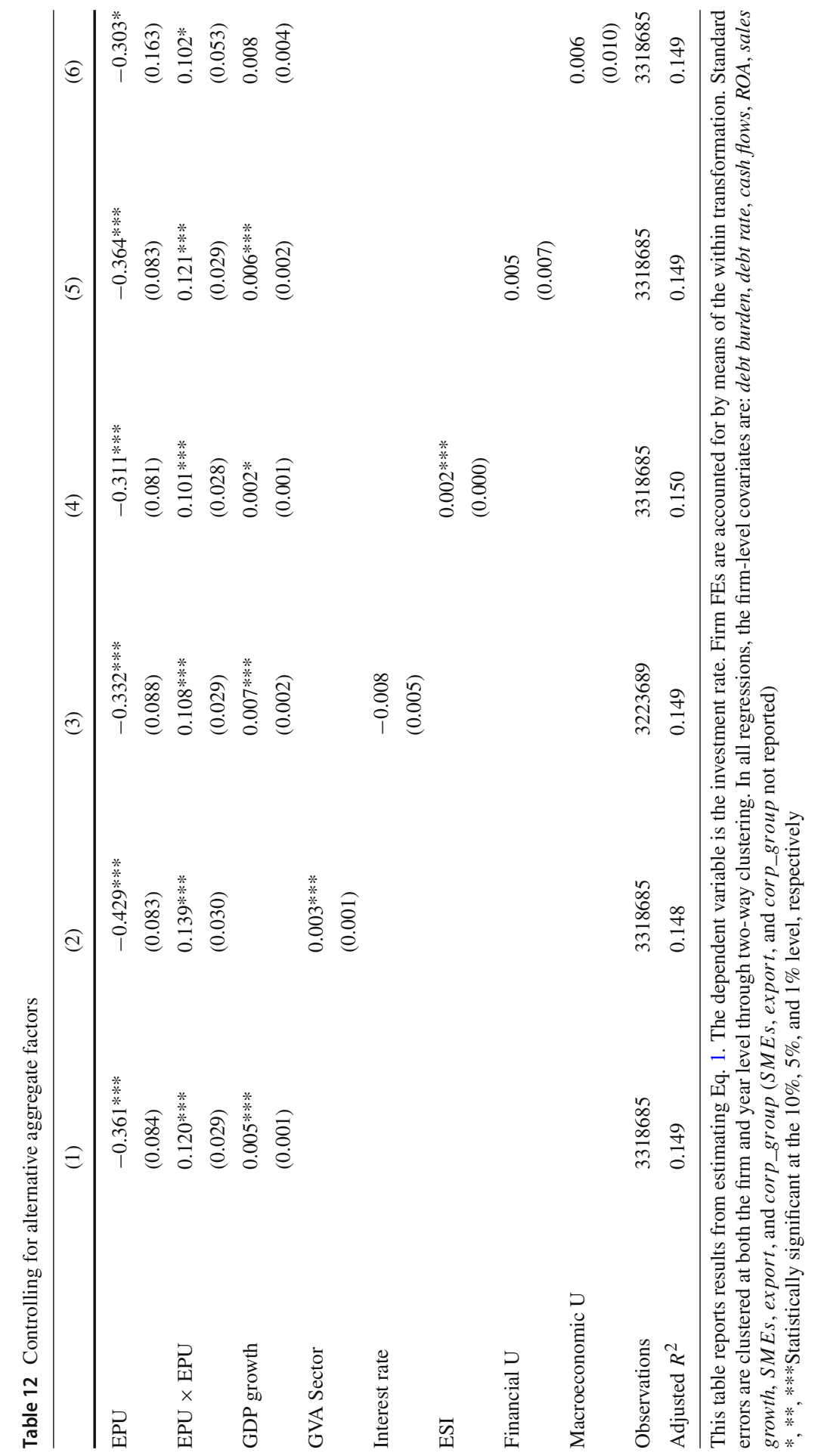


computed based on the Business and Consumer Surveys of the European Commission. We exploit questions asking firms about their expectations regarding future demand trends and compute a sector-specific measure of confidence about future demand. As expected, the ESI index has a significant positive effect on investment. Finally, we include a measure of financial and macroeconomic uncertainty, borrowing the two indexes developed by Gil et al. (2017). When simultaneously including these indexes with GDP growth, they both appear to have a non-significant effect on investment. For the case of macroeconomic uncertainty, neither the index nor our business cycle proxy appears to be significant. However, our diagnosis checks suggest that this specification may suffer from a problem of multicollinearity, as evidenced by the high VIF associated with GDP growth in the regression (roughly 11).

\section{F Corporate groups}

Using the information from the CBI database, we construct a proxy for the cost of debt in order to provide descriptive evidence about the relationship between belonging to a corporate group and the cost of accessing external finance. As previously mentioned, several authors emphasize the potential benefits of conglomerates for access to credit. Inderst and Müller (2003) and Faure-Grimaud and Inderst (2005) suggest that associations entail a lower risk of non-repayment than individual firms. Better access to credit may be also related to potential debt coinsurance provided by the conglomerate structure (Kuppuswamy and Villalonga 2016; Yan et al. 2010). However, other authors suggest that while conglomerates may bring the benefits of economies of scale to the access to credit, contagion effects due to idiosyncratic shocks among firms may prevail over coinsurance gains (Hege and Ambrus-lakatos 2002).

Our cost of debt variable is defined in the following way:

$$
\text { Cost of debt } t_{i t}=1 / 2 \times \text { Interest payments }_{i t} /\left(\text { Total debt } i t+\text { Total debt }_{i t-1}\right)
$$

Figure 7 depicts the evolution of our proxy for both groups of firms, as well as the proportion of firms belonging to a corporate group. Several things are worth noting. First, we observe a positive wedge in the cost of debt between firms belonging to a corporate group and the rest of the corporations throughout the entire period. The difference is found to be significant even after controlling for firm size, time dummies, and other possible determinants (see Table 13). Second, we find that the difference between the two groups becomes smaller after the Great Recession. This occurs at the same time as a significant increase in the proportion of firms belonging to corporate groups is taking place and could be related to a change in the composition of the sample of firms that belong to each group. 


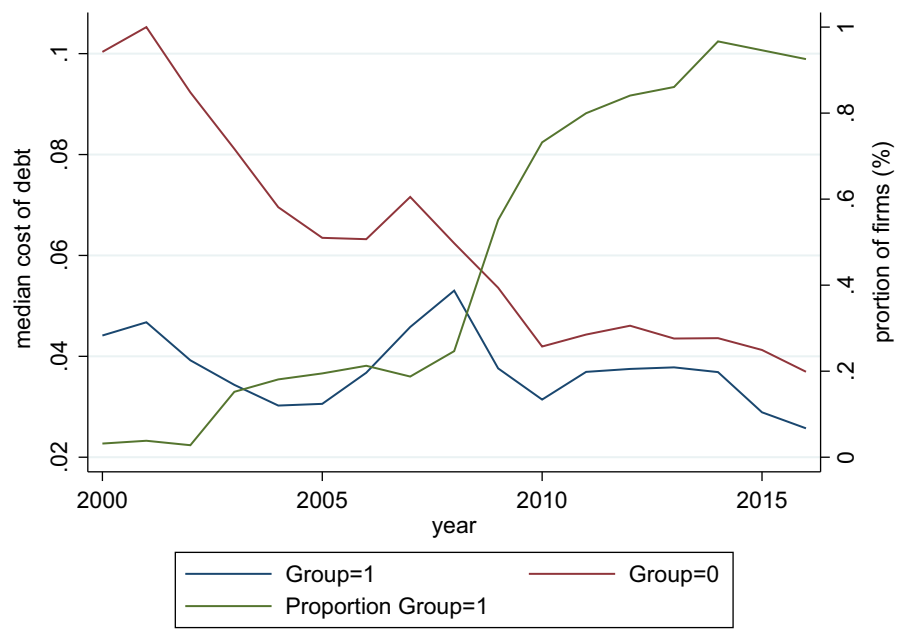

Fig. 7 Average cost of debt and proportion of firms belonging to a corporate group

Table 13 Descriptive evidence: Average cost of debt.

\begin{tabular}{ll}
\hline Cost of debt & $(1)$ \\
\hline Corp-group & $-0.024 * * *$ \\
& $(0.001)$ \\
Large company & $-0.023 * * *$ \\
& $(0.001)$ \\
Debt burden & $0.017 * * *$ \\
& $(0.000)$ \\
Sales growth & $-0.001 * * *$ \\
& $(0.000)$ \\
ROA & $-0.011 * * *$ \\
Observations & $(0.001)$ \\
$R^{2}$ & $3,125,532$ \\
\hline
\end{tabular}

$\overline{\text { OLS with time FEs and control variables. Standard errors are clustered }}$ at the firm level

$*, * *, * * *$ Statistically significant at the $10 \%, 5 \%$, and $1 \%$ level, respectively

\section{References}

Abel AB, Eberly JC (1994) A unified model of investment under uncertainty. Am Econ Rev 84(5):13691384

Alessandri P, Bottero M (2020) Bank lending in uncertain times. Eur Econom Rev 128:103503

Arellano C, Bai Y, Kehoe PJ (2019) Financial frictions and fluctuations in volatility. J Polit Econ 127(5):2049-2103

Arellano M, Bond S (1991) Some tests of specification for panel data: Monte carlo evidence and an application to employment equations. Rev Econ Stud 58(2):277-297 
Arellano M, Bover O (1995) Another look at the instrumental variable estimation of error-components models. J Econom 68(1):29-51

Bachmann R, Elstner S, Sims ER (2013) Uncertainty and economic activity: Evidence from business survey data. Am Econom J: Macroeconom 5(2):217-249

Baker SR, Bloom N, Davis SJ (2016) Measuring economic policy uncertainty*. Q J Econ 131(4):1593-1636

Bank of Spain (2016) Central Balance Sheet Data Office. Annual results of non-financial corporations 2016. Documentos de Trabajo, N. 1721

Basu S, Bundick B (2017) Uncertainty shocks in a model of effective demand. Econometrica 85(3):937-958

Bernanke BS (1983) Irreversibility, uncertainty, and cyclical investment. Q J Econ 98(1):85-106

Bertola G, Caballero RJ (1994) Irreversibility and aggregate investment. Rev Econom Stud 61(2):223-246

Bianco M, Bontempi M, Golinelli R, Parigi G (2013) Family firms' investments, uncertainty and opacity. Small Bus Econ 40(4):1035-1058

Bloom N (2009) The impact of uncertainty shocks. Econometrica 77(3):623-685

Bloom N (2014) Fluctuations in uncertainty. J Econom Perspectives 28(2):153-76

Bloom N, Bond S, Van Reenen J (2007) Uncertainty and investment dynamics. Rev Econom Stud 74(2):391415

Blundell R, Bond S (1998) Initial conditions and moment restrictions in dynamic panel data models. J Econom 87(1):115-143

Bonaime A, Gulen H, Ion M (2018) Does policy uncertainty affect mergers and acquisitions? J Finan Econom

Bontempi ME, Golinelli R, Parigi G (2010) Why demand uncertainty curbs investment: Evidence from a panel of Italian manufacturing firms. J Macroecon 32(1):218-238

Buch CM, Buchholz M, Tonzer L (2015) Uncertainty, bank lending, and bank-level heterogeneity. IMF Econom Rev 63(4):919-954

Cameron AC, Gelbach JB, Miller DL (2011) Robust inference with multiway clustering. J Business Econom Statist 29(2):238-249

Christiano LJ, Motto R, Rostagno M (2014) Risk shocks. Am Econ Rev 104(1):27-65

Dixit AK, Pindyck RS (1991) Investment under uncertainty. Princeton University Press, Princeton, US

Faure-Grimaud A, Inderst R (2005) Conglomerate entrenchment under optimal financial contracting. Am Econ Rev 95(3):850-861

Femminis G (2012, Jan) Risk aversion heterogeneity and the investment-uncertainty relationship. DISCE Quaderni dell'Istituto di Teoria Economica e Metodi Quantitativi itemq1260, Universitá Cattolica del Sacro Cuore, Dipartimenti e Istituti di Scienze Economiche (DISCE)

Fuss C, Vermeulen P (2008) Firms' investment decisions in response to demand and price uncertainty. Appl Econ 40(18):2337-2351

Ghirelli C, Perez JJ, Urtasun A (2019) A new economic policy uncertainty index for Spain. Econom Lett 182:64-67

Gil M, Pérez JJ, Urtasun A (2017, February) Incertidumbre macroeconómica: medición e impacto sobre la economía española. Artículos analíticos, Bank of Spain

Gilchrist S, Sim JW, Zakrajšek E (2014, April) Uncertainty, Financial Frictions, and Investment Dynamics. NBER Working Papers 20038, National Bureau of Economic Research, Inc

Guiso L, Parigi G (1999) Investment and demand uncertainty. Q J Econ 114(1):185-227

Gulen H, Ion M (2016) Policy uncertainty and corporate investment. Rev Financial Stud 29(3):523-564

Hege U, Ambrus-lakatos L (2002) Internal capital markets: The insurance-contagion trade-off. SSRN Electron J. https://doi.org/10.2139/ssrn.302799

Inderst R, Müller HM (2003) Internal versus external financing: An optimal contracting approach. J Financ 58(3):1033-1062

Jens CE (2017) Political uncertainty and investment: Causal evidence from U.S. gubernatorial elections. J Financ Econ 124(3):563-579

Julio B, Yook Y (2012) Political uncertainty and corporate investment cycles. J Financ 67(1):45-83

Julio B, Yook Y (2016) Policy uncertainty, irreversibility, and cross-border flows of capital. J Int Econ 103:13-26

Jurado K, Ludvigson SC, Ng S (2015) Measuring uncertainty. Am Econ Rev 105(3):1177-1216

Kuppuswamy V, Villalonga B (2016) Does diversification create value in the presence of external financing constraints? evidence from the 2007-2009 financial crisis. Manage Sci 62(4):905-923

Leahy JV, Whited TM (1996) The effect of uncertainty on investment: Some stylized facts. J Money, Credit Banking 28(1):64-83 
Petersen MA (2009) Estimating standard errors in finance panel data sets: Comparing approaches. Rev Financ Stud 22(1):435-480

Saltari E, Ticchi D (2007) Risk aversion, intertemporal substitution, and the aggregate investmentuncertainty relationship. J Monetary Econom 54(3):622-648

Shoag D, Veuger S (2016) Uncertainty and the geography of the great recession. J Monetary Econom 84:84-93

Wooldridge JM et al (2001) Econometric analysis of cross section and panel data. MIT Press, Cambridge, Massachusetts

Yan A, Yang Z, Jiao J (2010) Conglomerate investment under various capital market conditions. J Bank Finance 34(1):103-115

Publisher's Note Springer Nature remains neutral with regard to jurisdictional claims in published maps and institutional affiliations. 